\title{
الاقتصاد الإسلامي إلى ما وراء الوضعية والمعيارية
}

عبد الرزاق بلعباس

الملخص

يتناول هذا البحث استخدام البُعدين: المعياري والوضعي في الخطاب الاقتصادي الإسلامي، استنادًا إلى عينة

شنملت اثني عشر باحثًا، عبر الطريقة الإدراكية: إلى أي شيء يصلح؟ وقد خلصت إلى أن استخدام ثنائية "وضعي/ معياري" في الاقتصاد الإسلامي ما زال يفترض وجود حد فاصل بين ما يسمى بالوضعي وما يسمى بالمعياري، وهو

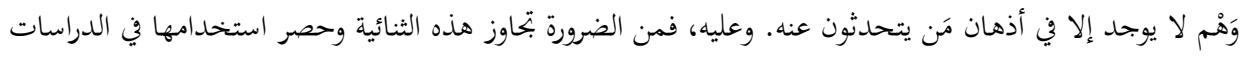

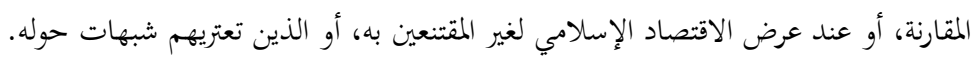

الكلمات المفتاحية: المنهجية، الاقتصاد الإسلامي، الوضعية، المعيارية.

\section{Islamic Economics beyond Positivism and Normativism}

\section{Abstract}

This paper addresses the use of the normative and positive prepositions in the Islamic economic discourse, based on responses of a sample of twelve researchers, using the cognitive method: What is used for? It concluded that the use of the dichotomy "positive vs. normative" in Islamic economics still assumes the existence of a clear-cut boundary between what it is called 'positive' and 'normative'. The paper considers such a preposition as an illusion that exists only in the minds of those who talk about it. In this regard, it is necessary to go beyond this dichotomy and restrict its use to comparative studies, or when it comes to present Islamic economics to those who are not convinced of it, or those who have suspicions of it.

Keywords: Methodology, Islamic economics, positivism, normativism.

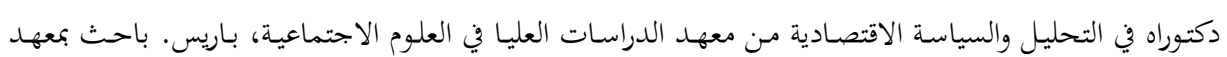
الاقتصاد الإسلامي، جامعة الملك عبد العزيز- السعودية. البريد الالكتروني: abelabes@kau.edu.sa

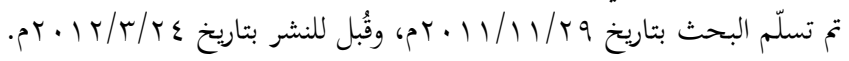




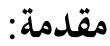

منــ نــو ثلـث قـرن دخـل مفهومـا "الاقتصـاد الوضـعي" "والاقتصـاد المعيـاري" في أدبيـات الاقتصـاد الإسـلامي. وتمخضض عـن ذلك تسـاؤلات، مـن مثـل: هـل الاقتصـاد الإسلامي اقتصاد معياري؟ أو اقتصاد وضعي؟ أو مزيج منهما؟ أو وسط بينهما؟ وهي أسئلة تعكس استحالة فصل مفهوم الاقتصاد عن الإشكالات التي انبثقت عنه في بيئته الأصلية، وتطرح ضرورة الوقوف على هذه الإشكالات وتحديد ثقلها المعريف في بلورة أبعاد التصـور الإسـلامي للاقتصـاد، ومـا ينـدرج تحته مـن قضـايا ومسـائل. فالتفاعل المعريف في

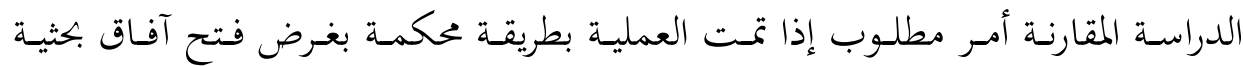
جديدة. أمّا أن يصبح هذان المفهومان هما الأصل، وصياغة الاقتصاد الإسلامي بأبعاده المختلفة تابعة لمما، فهذا يثير تساؤلات عن المنظومة الإدراكية التي تقف وراء عملية بناء الفكر الإسلامي للاقتصاد، وطريقة الاستشهاد بالنصوص الشرعية.

لهذا كانت الحاجة ملحة لتسليط الضوء على أسباب الربط بين الاقتصاد الإسلامي

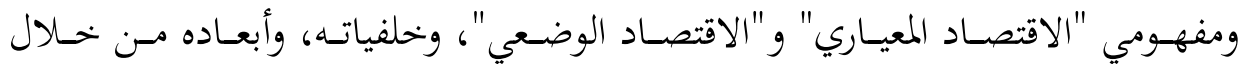
السؤال الرئيس الآتي: ما دوافع استخدام مفهومي الاقتصاد المعياري والاقتصاد الوضعي في الاقتصاد الإسلامي؟ ويتفرّع منه السؤالان الآتيان:

• مـا الخلفيـات والأبعـاد المعرفيـة والنظريـة والفلسـفية الـتي تحملهـا ثنائيـة "وضسعي/ معياري"

• مـا استخدامات المقاربتين: الوضعية والمعيارية في الاقتصاد الإسلامي؟ وما آثارها في الإنتاج المعري لهذا الحقل؟

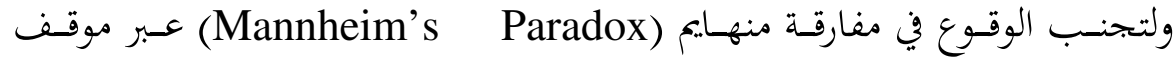
أيديولوجي مسبق، ' يَتمّ التطرق إلى موضوع الورقة عبر الطريقة الإدراكية ( cognitive ' تعني مفارقة منهايم استحالة التطرق إلى الأيديولوجيا من دون أيديولوجيا مسبقة؛ انظر المرجع الآتي: - Mannheim, Karl. Idéologie et utopia. Une introduction à la sociologie de la connaissance, Paris: Librairie Marcel Rivière et Cie, 1956, 
method مرة في حقل الاقتصاد الإسلامي.

تتضمن الورقة عينة من اثني عشر باحثًا تمّ انتقاؤها وفق معيارين أساسيين:

أولاً: التنـوع المعـرفي والإضـافة العلميـة بغض النظر عـن الموافقـة أو المخحالفـة لما هـو

$$
\text { مطروح من أفكار. }
$$

ثانيـاً: قصسب السبق في الكتابـة؛ نظرًا إلى تـأثير أطروحـات الجيل الأول والثناني مـن الباحثين في الاقتصاد الإسلامي في الجيل الجديد، وهو أمر لا يخفى على المطلعين.

\section{أولاً: موقـع مفهـومي "الاقتصـاد الوضـعي" و "الاقتصـاد المعيـاري" في الاقتصـاد التقليدي}

يتفـق البـاحثون على أن الاقتصـادي البريطـاني جـون نيفيـل كينـز؛ والــ الاقتصـادي

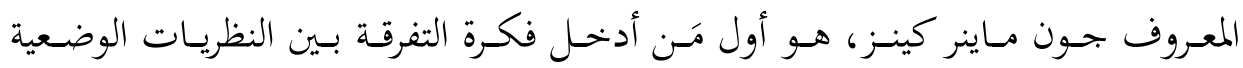

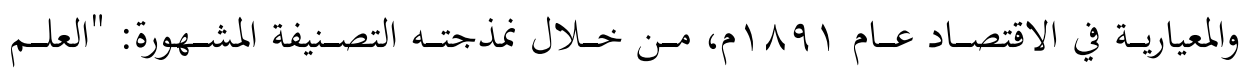

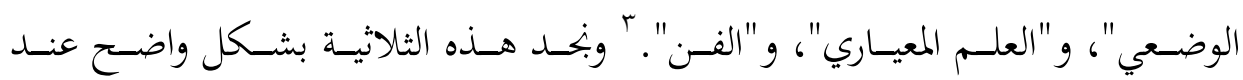
الاقتصادي الفرنسي فرنسوا سيميان؛ إذ يقول: "إذا كان موضوع علم الاقتصاد هو معرفة

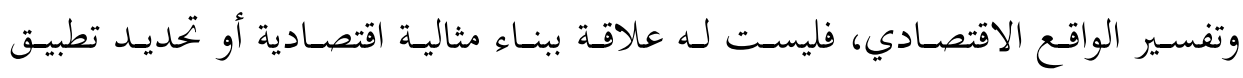

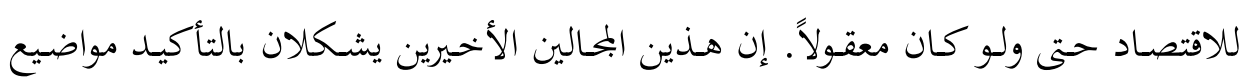

translated from his book 'Ideology and Utopia: An Introduction to the Sociology of Knowledge', Mariner Books, 1955:

http://classiques.uqac.ca/classiques/Mannheim_karl/mannheim_karl.htm.

${ }^{2}$ Belabes, Abderarzak. Compétitivité nationale, archéologie d'une notion et d'un débat, thèse de doctorat, Paris, Ecole des Hautes Etudes en Sciences Sociales, 2001.

${ }^{3}$ Keynes, John Neville. The Scope and Method of Political Economy, 1890, Fourth Edition 1917, New York: Kelley Reprints of Economic Classics, 1963, p. 34. 
بحـث مشـروعة ومفيـدة ومهمهـة وربمـا ضـرورية، ولكنهمـا يرتبطـان بفـرع معري معيـاري أو

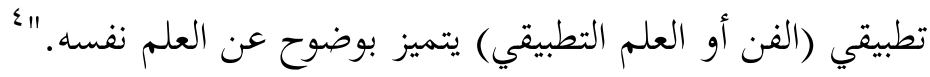

ورغــم أن جـون نيفيـل كينـز ينتسـب إلى الفلسـفة الوضـعية، فإنسه لا ينفـي وجـود

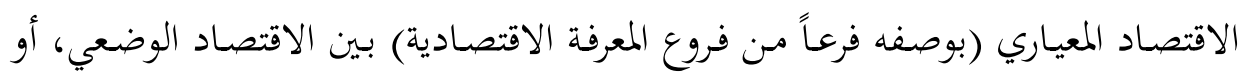

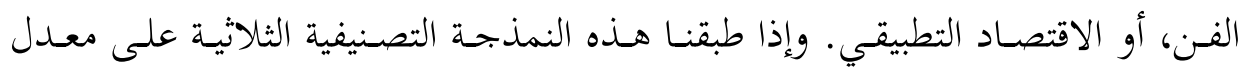
الفائدة، فإنَّ النظرية الوضعية تدرس القوانين التي تحدِّد المستوى الفعلي لمعدل الفائدة، في

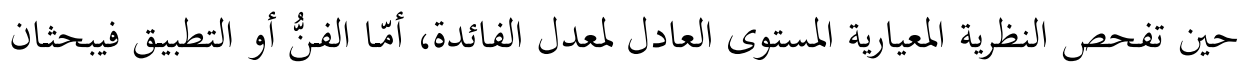
عن الوسائل اللازمة لعمل ذلك مـن خهلال السياسة الاقتصادية التي تسمح بالاقتراب، بقدر الإمكان من هذا المعدل العادل.

\section{I ـ تعريف مفهومي "الاقتصاد المعياري" و "الاقتصاد الوضعي":}

لا يوجد تعريف لفرع من علم الاقتصاد مستقل قائم بذاته اسمه "الاقتصاد المعياري"؛

لأنّ هذا الأخير يشمل كل ما لا ينتمي إلى الاقتصاد الوضعي. فيلحق بالاقتصاد المعياري

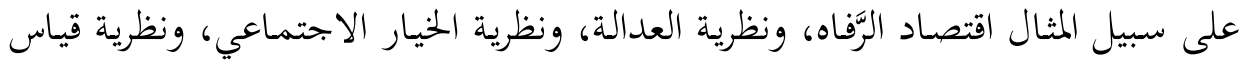

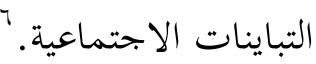

ويُقصَــد بمصـلح "الاقتصـاد المعيـاري" المنظـور المعيـاري أو المقاربـة المعياريـة لعلـم الاقتصاد. \ وهذا يفسّر الحرج الذي يجده أبرز الاقتصاديين في القرن العشرين وهو يحاول تعريف "الاقتصاد المعياري"؛ إذ اكتفى بتعريف عام مؤداه أن الاقتصاد المعياري يأخذا "ما فئ

${ }^{4}$ Simiand, François. La méthode positive en sciences économiques, Paris: Alcan, 1912, p. 5.

${ }^{5}$ Keynes, John Neville. op. cit., p. 33.

6 Fleurbaey, Marc. Applications de l'économie normative, Revue d'économie politique, No.1, Volume 117, 2007, p.1.

7 Jacquemin, Alexis, Tulkens, Henry et Mercier, Paul. Fondements d'économie politique, Bruxelles: De Boeck Université, 2002, p. 7 ; Jurion, Bernard. Economie politique, Bruxelles: De Boeck Université, 2006, pp. 11-12. 
يجبـ أن يكون"، أو الأحكام القيمية، أو الأهـداف أو السياسة الاقتصادية العامـة بعين

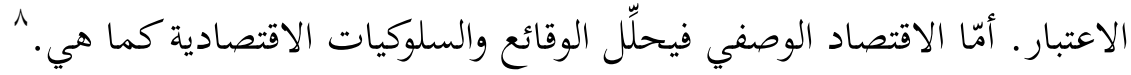
ويبرز هذا التخبط الدلالي في إيباد تعريف جامع مانع عند النظر إلى التعريف الآتي: "إن الاقتصـاد الوضـعي هـو فـرع مـن علـم الاقتصـاد يتعلـق بوصـف وتفسـير الظـواهر الاقتصـادية، بينمـا يغطي الاقتصـاد المعياري الحقـل الفكري المخصص لتطبيق الاقتصـاد الوصفي بهدف تقديم المشاورات العملية بشأن المشكلات بما في ذلك تلك التي تتعلق

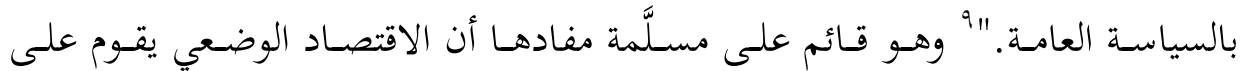
مقاربة وصفية بحردة لا يتدخل فيها الميل الذاتي والحكم القيمي.

\section{r ب الأشكال المتعددة لثنائية "وضعي/ معياري":}

تحمل ثنائية "وضعي/معياري" في الذاكرة الجماعية الأوروبية نزاعات ظاهرة وخفيـة

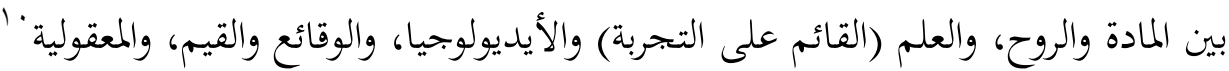
والمسؤولية، والحرية الفردية والخيـارات الجماعية، والموضسوعية المحردة مـن الأحكام القيمية واللاموضوعية المشتملة على أحكام قيمية. ويمكن تلخيص هذه التقابلات الاصطلاحية

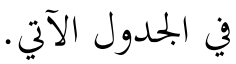

\begin{tabular}{|c|c|}
\hline الاقتصاد المعياري & \\
\hline الأيديولوجيا & القيماد الوضعيم \\
\hline
\end{tabular}

' سامويلسون، بول، ونورهاوس، ويليام. الاقتصـاد، ترجمة الطبعة الخامسة عشرة، عمان: الأهلية للنشر والتوزيع، . $\vee \wedge \varepsilon$ ص

${ }^{9}$ Wong, Stanley. Positive Economics, in Eatwell, John et al., The New Palgrave: A Dictionary of Economics, Vol. 3, 1988, p. 920. "' خحلافًا لما هو سائد في أدبيات الاقتصاد الإسلامي، نفضّل ترجمة كلمة (rationality) ب" لمعقولية" بدلاً من

Reig, Daniel. Larousse As-Sabil arabe français / français arabe, Paris: Editions Larousse, $1989, \mathrm{n}^{\circ} 3601$. 


\begin{tabular}{|c|c|}
\hline الموضوعية & اللاموضوعية \\
\hline وصفي & إرشادي \\
\hline التحليل الاقتصادي & النظام الاقتصادي \\
\hline
\end{tabular}

\section{r. بين الاقتصاد الوضعي والاقتصاد السياسي:}

شهدت بداية ثمانينات القرن التاسع عشر تنازعًا في المناهج؛ أي في الطريقة التي يتمّ

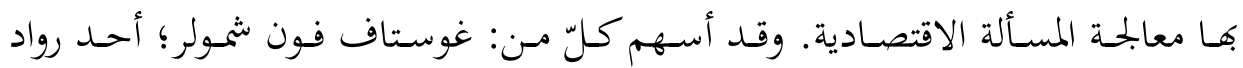

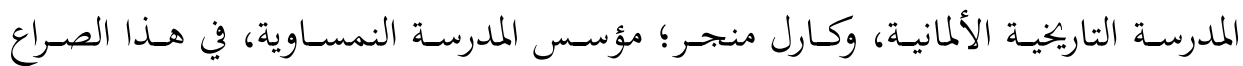

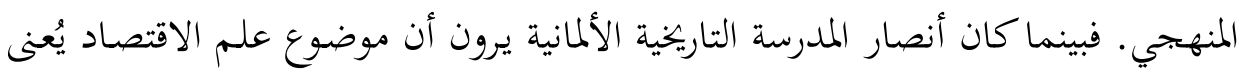

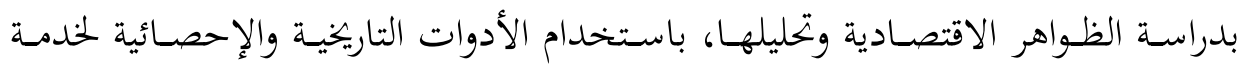

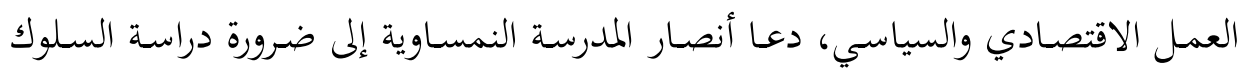

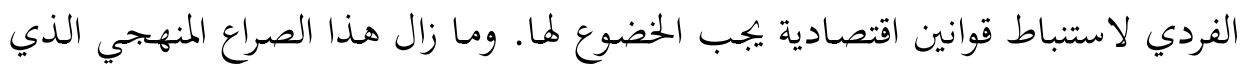
يدور حول هوية علم الاقتصاد وموضوعه قائمًا إلى اليوم، بناء على سؤالين أساسيين: • هـل يقتصـر علـم الاقتصـاد على دراسـة مـا هـو كـائن (علـم الاقتصـاد = علمـاً وضعيّاً)؟

• هل يشمل علم الاقتصاد دراسة ما هو كائن وما ينبغي أن يكون (علم الاقتصاد

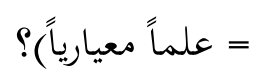

ففي الوقت الذي يـرى فيـه الاقتصـاديون الوضعيون، وعلى رأسهم الأمريكي ميلتون

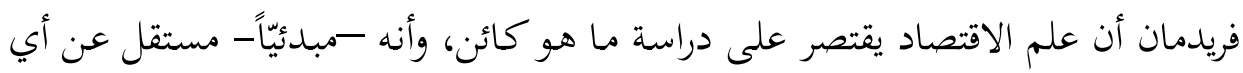

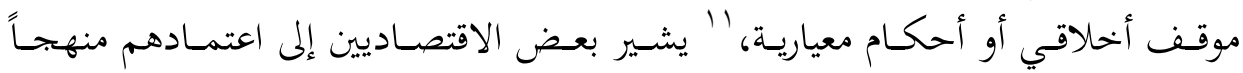

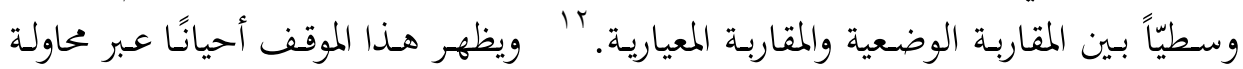

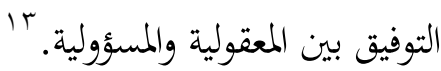

11 Friedman, Milton. Essays in Positive Economics, Chicago: The University of Chicago Press, 1953, p. 4.

${ }^{12}$ Jacquemin, Alexis et al. Op. cit., p. 8.

13 Löwenthal, Paul. L'économie politique entre rationalité et responsabilité, INRA - Groupe Ethos Ethique, Science et société, 2000. 


\section{ع ـ انهيار ثنائية "وضعي/معياري":}

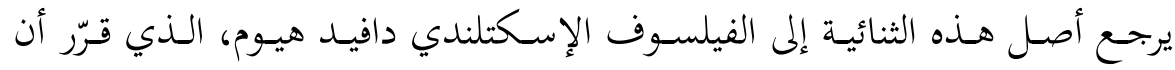

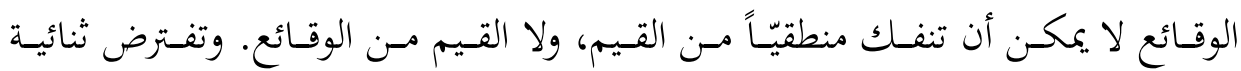
"وضعي/معياري" ما يأتي:

• تغطية الحقل الوضعي والحقل المعياري تغطية كاملة لحقل المعرفة، ومن تَّمّا لا توجد معرفة اقتصادية خارج نطاق المقاربتين: الوضعية، والمعيارية. • وجود حدّ فاصل بين ما يتمي إلى الحقل الوضعي وما يرتبط بالحقل المعياري.

وقد لقيت هذه الثنائية انتقادًا شديدًا من المتخصصين في علم اجتماع المعرفة والمنهجية

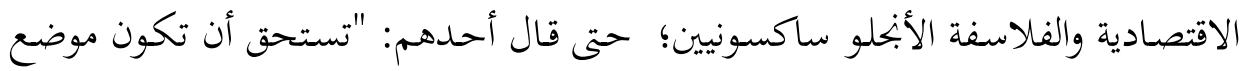

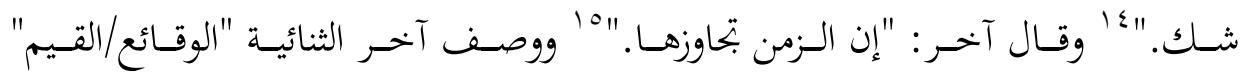

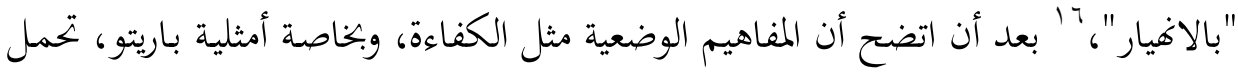

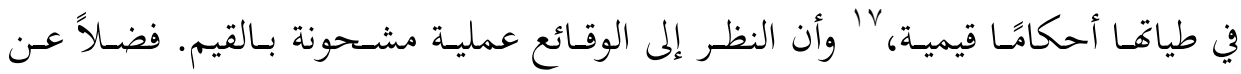

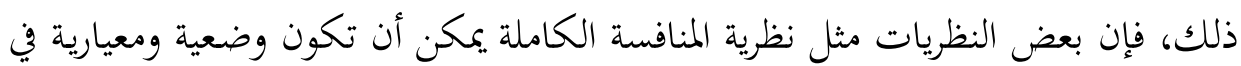

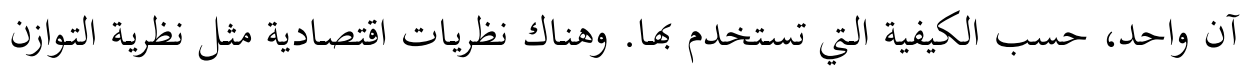

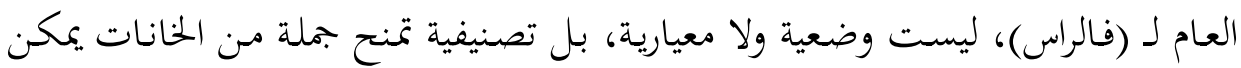

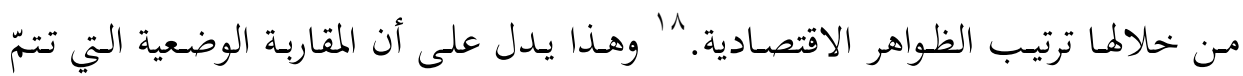

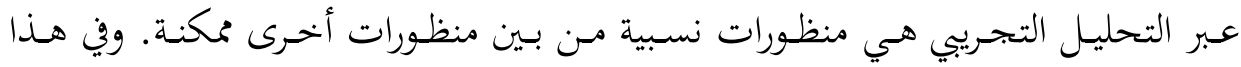

${ }^{14}$ Boudon, Raymond. Le juste et le vrai. Etudes sur l'objectivité des valeurs et de la connaissance, Paris: Fayard, 1995, p. 84.

${ }^{15}$ Blaug, Marc. La pensée économique, traduit de l'anglais, 4e édition, Paris: Economica, 1986, p. 210.

${ }^{16}$ Putnam, Hilary. Fait/valeur: Un dogme, Paris: Alcan, 2004, pp. 15-36, translated from his book 'The Collapse of the Fact/Value Dichotomy and other essays', Cambridge: Harvard University Press, 2004.

${ }^{17}$ Blaug. Op. cit., p. 722.

${ }^{18}$ Blaug. Op. cit., pp. 8-9. 
الصـدد يقـول المفكر الفرنسي رونيـه غينـون: "إن الاقتصـاد الغربي لم يقـترح لنفسـه أبـلًا

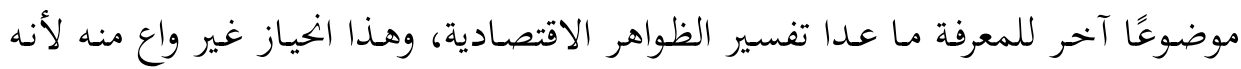

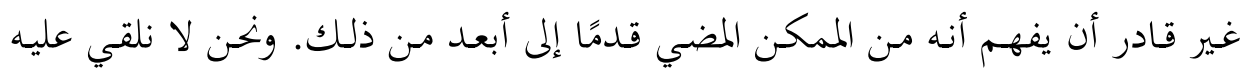

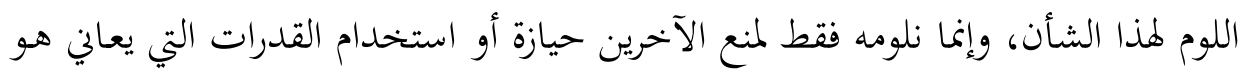
من نقص فيها. "19 الموان

\section{هـ بين ما يجب أن يكون وما ينبغي أن يكون:}

يحمـل مفهـوم الاقتصـاد المعيـاري نـزاعاً بـين "مـا يجــب أن يكـون"، و "مـا ينبغـي أن يكون"، يتبلور بشكل خاص في الأدبيات الفرنسية والإنحليزية على النحو الآتي:

\begin{tabular}{|c|c|c|}
\hline اللغة الانجليزية & اللغة الفرنسية & اللغة العربية \\
\hline What ought to be & Ce qui doit être & ما يجب أن يكون \\
\hline What should be & Ce qui devrait être & ما ينبغى أن يكون \\
\hline
\end{tabular}

وإذا كان هذا التفريق الدلالي يبدو ثنائيّاً عند القارئ العربي، فإنه يعبِّر في الأدبيات

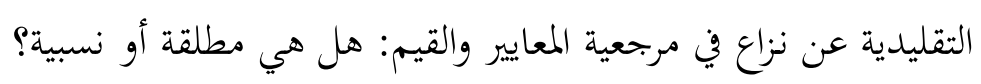

• إن عبارة "ما يجب أن يكون" لما دلالة دينية، أمّا عبارة "ما ينبغي أن يكون" فإها تحمل

طابعًا علمانيّاً.

• إن عبارة "مـا يجـب أن يكون" تستلزم معايير مطلقة غير قابلة للنقد والتغيير، أمّا

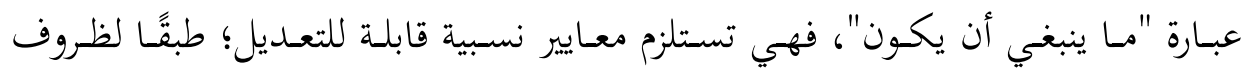
التطور الاقتصادي ومقتضيات التطبيق.

• إن وراء عبارة "ماذا يجبـ أن يكون" أمراً وإلزاماً فاصلاً، في حين أن وراء عبارة "ما

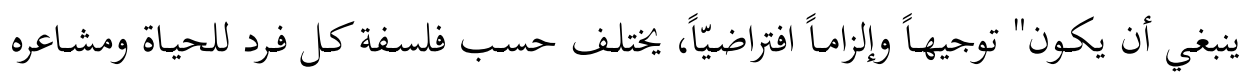
الخاصة. يقول الاقتصادي البلجيكي بول جوريون في مقدمة كتابه "الاقتصاد السياسي":

${ }^{19}$ Guénon, René. Orient et Occident, Paris: Editions de la Maisnie, 1987, p. 46 . 
"تستلزم المقاربة المعيارية أحكاماً متعلقة بالأخلاقيات، أو أحكاماً متعلقة بالقيم. ولا توجد أحداء

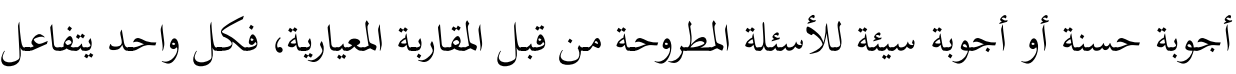
معها وفقاً لمشاعره الخاصة. هل ينبغي إعطاء الأولوية لمدف العمالة الكاملة أم على نقيض فيض المعائه

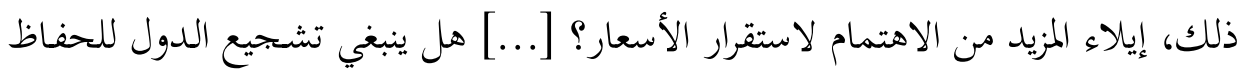

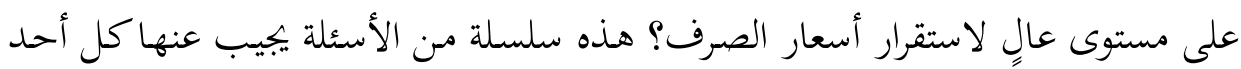

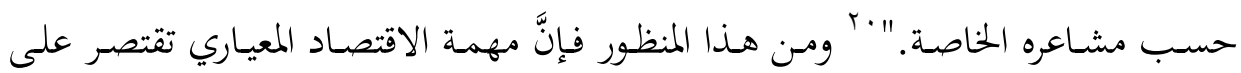
تقديم اقتراحات للحقل السياسي من دون تحديد أفضلها.

\section{7. عودة الاقنصاد المعياري إلى الساحة الأكاديمية:}

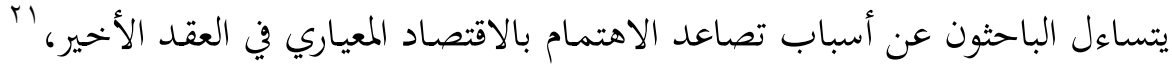
بعـد أن سيطر الاقتصـاد الوضعي على الأبحاث الأكاديمية طوال عقود، وبعـد أن كـادت

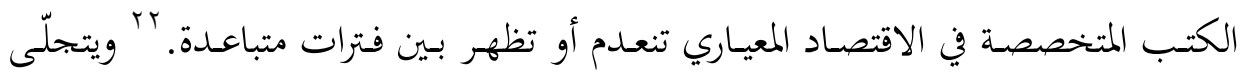
هذا الميل من إعادة قراءة تاريخ الفكر الاقتصادي؛ بغية الوصول إلى نتيجة مفادها: أنّ علم

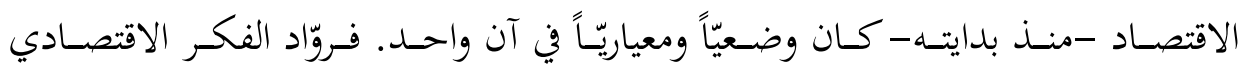
التقليديون، وبخاصة آدم سميث، على نقيض مـا هو شائع، لم ينشغلوا بقضية فصل القيم

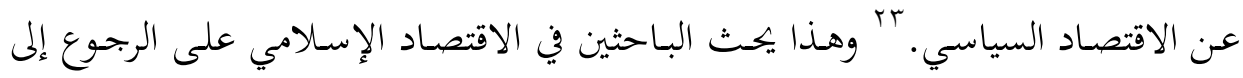
المراجع الأصلية وعدم قراءها عبر المنظور السائد.

${ }^{20}$ Jurion. Op. cit., p. 12.

${ }^{21}$ Lallement, Jérôme, Frydman, Roger, Brochier, Hubert et Gazier Bernard. L'économie normative, Paris: Economica, 1997; Lerroux Alain et Livet Pierre. Economie normative et philosophie morale, Paris: Economica, 2006 ; Fleurbaey, Marc et Mongin, Philippe. Economie normative, Paris: Presses de Sciences Po, 2007.

${ }^{22}$ Bergson, Abram. Essays in Normative Economics, Cambridge: Belknap Press of Harvard University Press, 1966; Mishan, Edward. Introduction to Normative Economics, Oxford: Oxford University Press, 1981.

${ }^{23}$ Maréchal, Jean-Pierre. Ethique et économie. Une opposition artificielle, Rennes: Presses Universitaires de Rennes, 2005. 


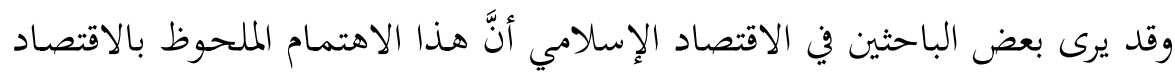

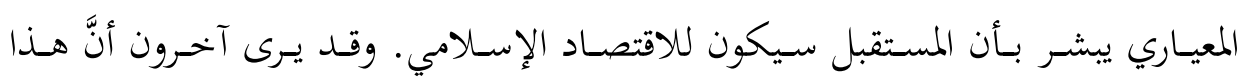

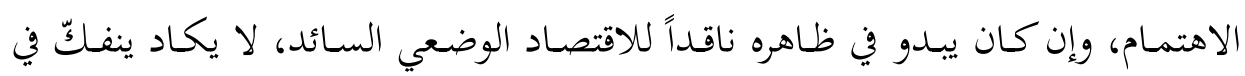

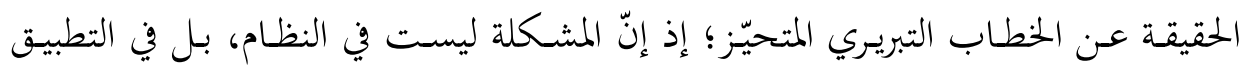

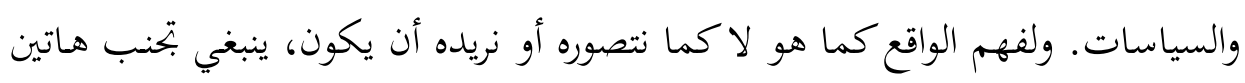

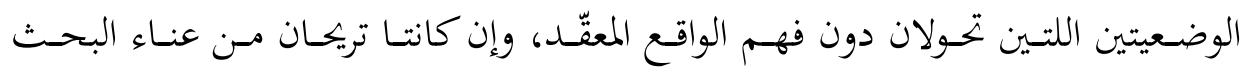

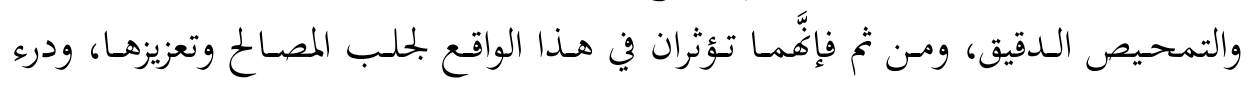

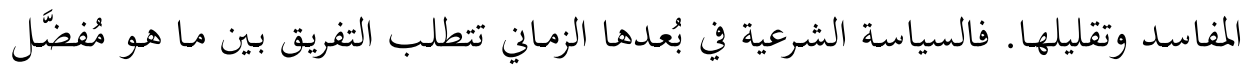
وما هو يُمكِن في ظل الحخيارات المتاحة والإمكانات المتوافرة. ويُّسجّل الاقتصـادي الفرنسي رينيـه باسي أنَّهـ عندما كانـت "المعقوليـة الوسـائلية" instrumental rationality

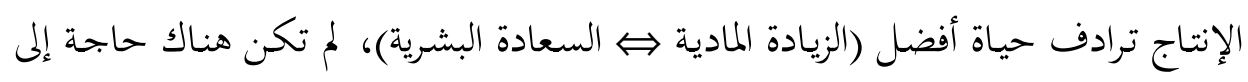

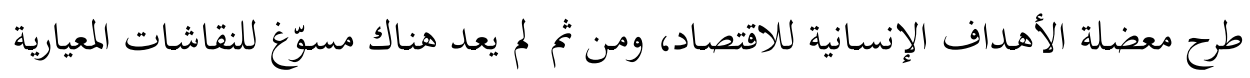

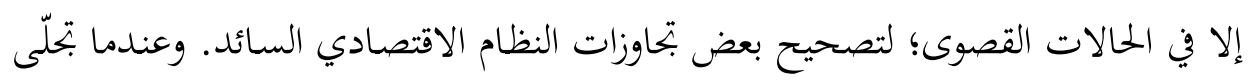

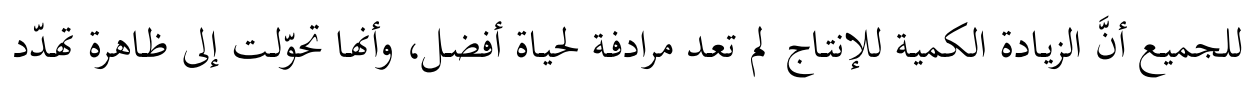

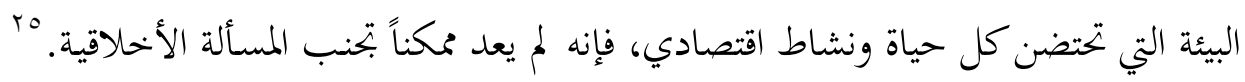

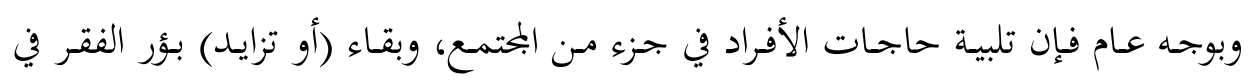

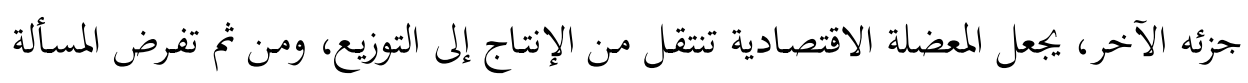

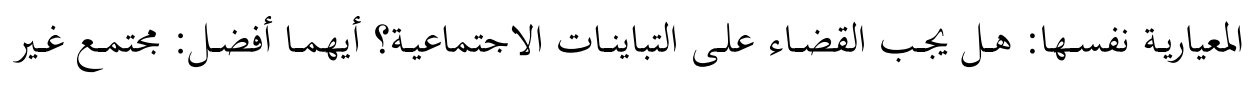

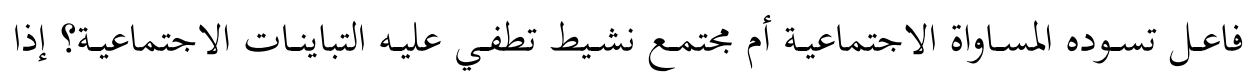

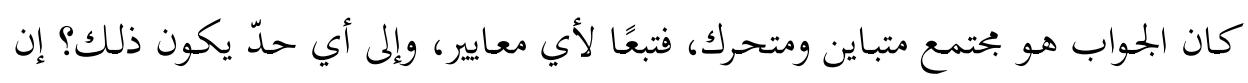

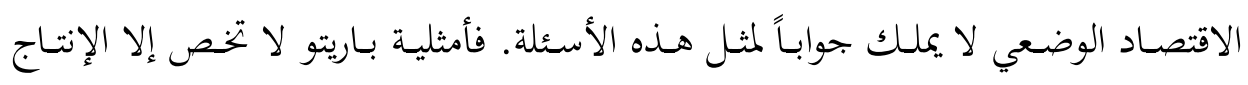

گَ تقتصر "المعقولية الوسائلية" على إيجاد الوسائل الناجعة، أمّا الرشد المعياري فيؤخَذ به لحل المهام الأخلاقية. 25 Passet, René. L'émergence contemporaine de l'interrogation éthique en économie, Paris: UNESCO, 2003, p. 6. 
استنادًا إلى نظام توزيع معين، ومن ثم لا توجد مثل هذه الأمثلية على مستوى التوزيع. وهذا

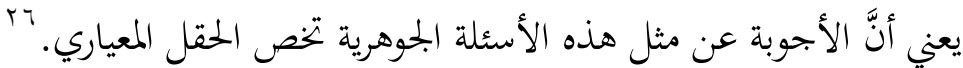

ثانيَّا: موقـع مفهـومي "الاقتصـاد الوضـعي" و "الاقتصـاد المعيـاري" في الاقتصـاد الإسلامي

بـــأ الاهتمــام بمفهـومي "الاقتصـاد الوضــي" و "الاقتصــاد المعيـاري" في أدبيـات الاقتصاد الإسلامي منذ ثلث قرن على الأقل؛ إذ تطرق إليها -مثثلاً- أحد المشاركين في

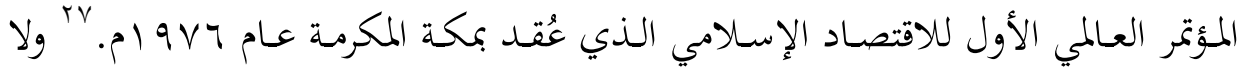

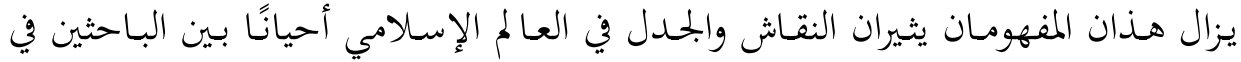

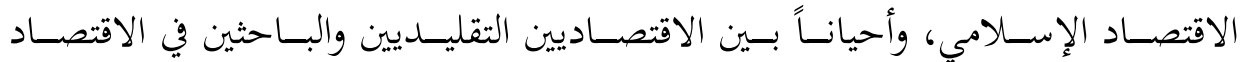
الإسـلامي. ففي "حوار حسول الاقتصاد الإسـلامي"، نظمه مركز صالح كامـل للاقتصـاد

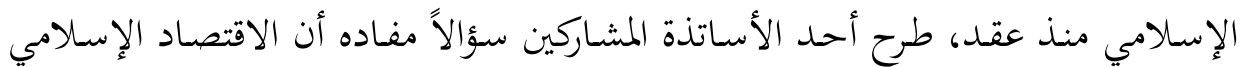

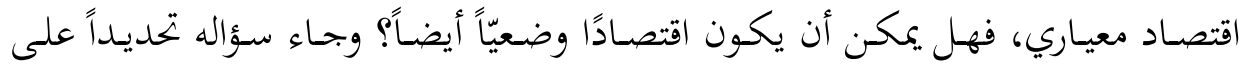

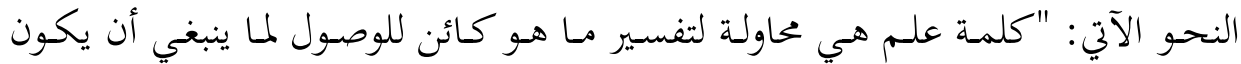

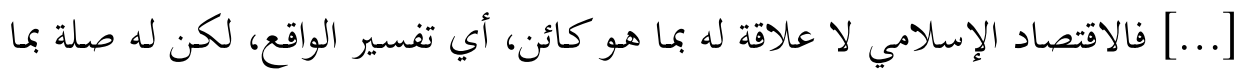

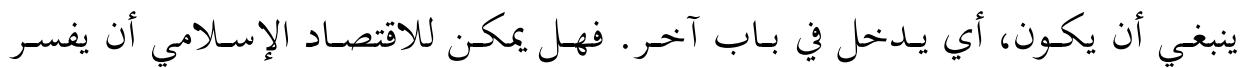

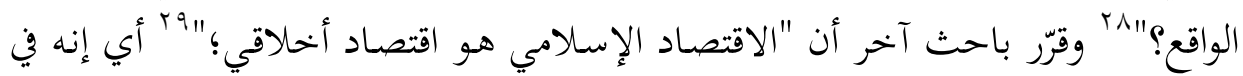

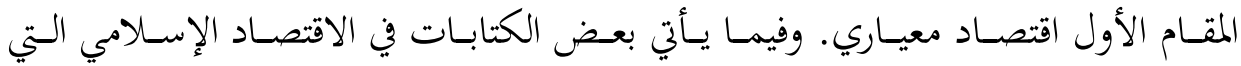

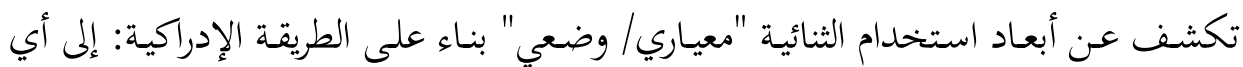

شيء تصلح؟

${ }^{26}$ Passet. Op. cit., p. 7.

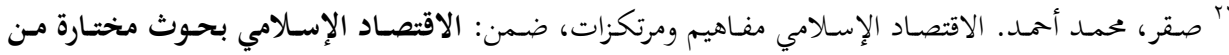

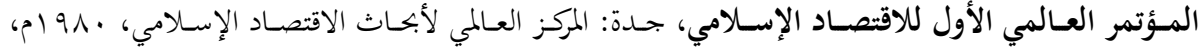

ص ص

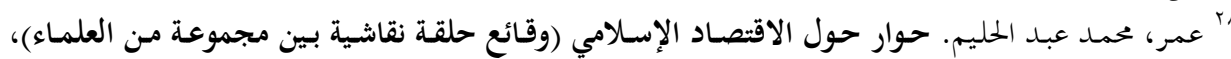

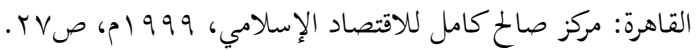

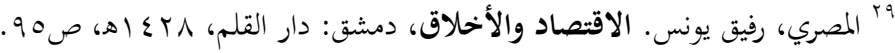




\section{ا ـ عدم لزوم ثنائية "اقتصاد معياري/ اقتصاد وضعي":}

في ورقة عنواها "الاقتصاد الإسلامي بوصفه علماً اجتماعيّاً، طرح حممد عبد المنان

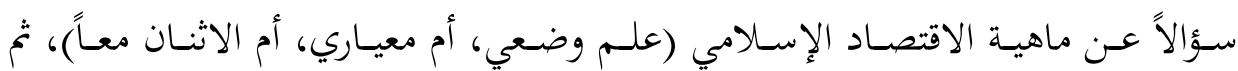

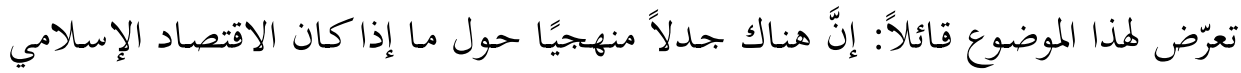

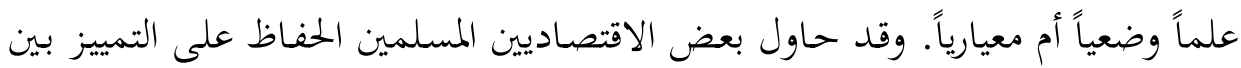
العلم الوضعي والعلم المعياري، وبالتالي إفراغ التحليل الاقتصـادي الإسلامي في القالب

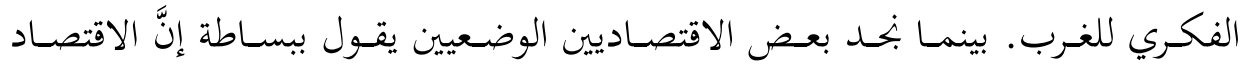
الإسهلامي علم معياري." فالاقتصاد الإسلامي في نظره "ليس علمـاً وضعيّاً ولا معيارياً:

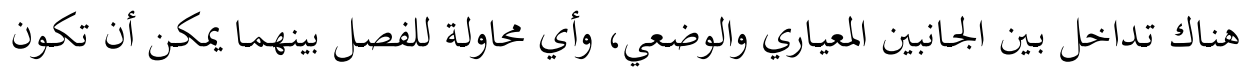

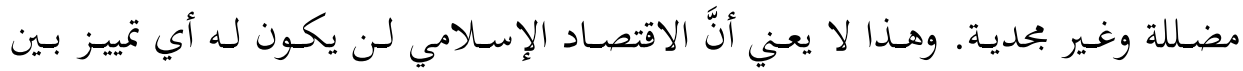

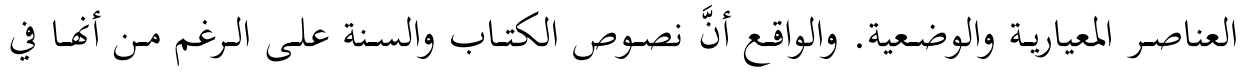

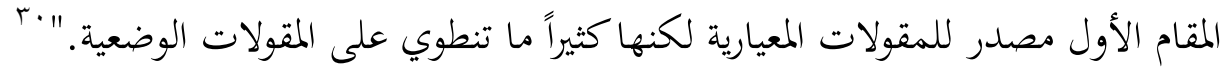

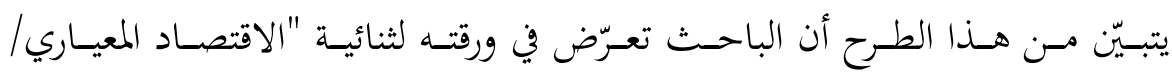

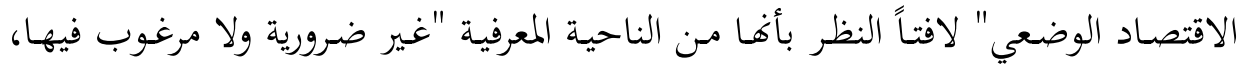

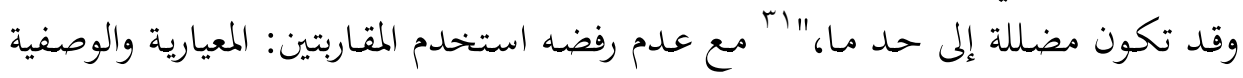

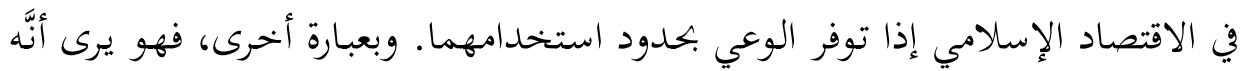

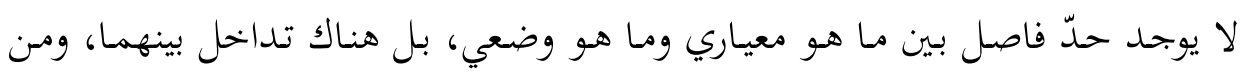

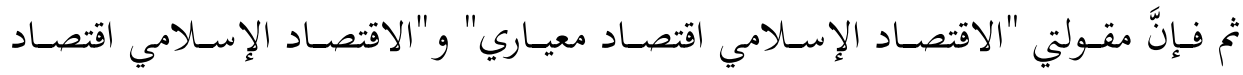

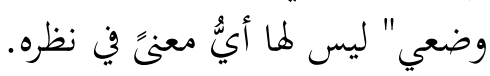

\section{Y . تحقيق إسلامية علم الاقتصاد:}

في ورقة عنواها "تحقيق إسلامية علم الاقتصاد: المفهوم والمنهج"، يسعى أنس الزرقا إلى الإجابة عن سؤالين، هما:

30 Abdul Mannan, Muhammad. Islamic Economics as a Social Science, Journal of Research in Islamic Economics, Vol. I, No.1, Summer, 1983, pp. 53-54.

${ }^{31}$ Abdul Mannan. Op. cit., p. 60. 


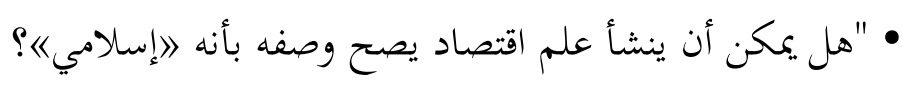
• هل يعني ذلك إنكار وجود سنن (قوانين) اقتصادية عالمية شاملة لجميع النظم

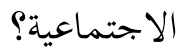

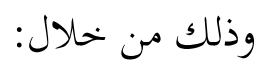

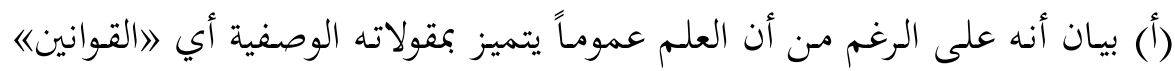

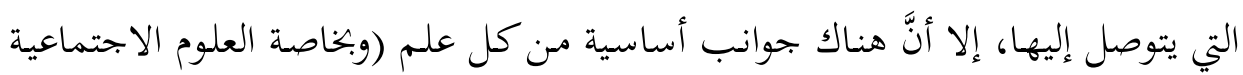
ومنها الاقتصاد) لا مفر لأي باحث أن يستند فيها لقيم سابقة. كنبا (ب) أن نصـوص الشـريعة الإسـلامية على الرغم مـن أغَّا، أساسـاً، مصـدر للقيم لكنها كثيراً ما تنطوي على مقولات وضعية عن الحياة الاقتصادية. فإذا تم استبدال القيم التي لا بدّ أن يستند إليها علم الاقتصاد -المذكورة في النقطة

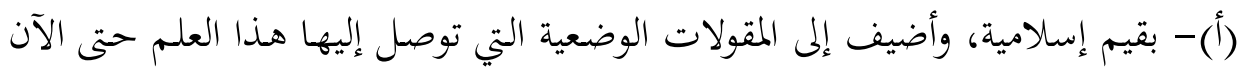

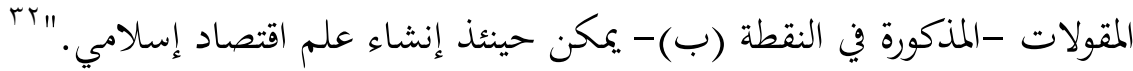
ويطرح الباحث من هذا الاستدلال المنهجي نقطتين أساسيتين مترابطتين: أولاً: استحالة كتابة مقالة وصفية من دون الاستناد إلى قيم مسبقة. ثانياً: استحالة الفصل بين ما ينتمي إلى الحقل الوضعي وما ينتمي إلى الحقل المعياري. بناءً على هذين الاستتاجين، يستخدم الباحث المقاربتين: المعيارية والوضعية في بلورة

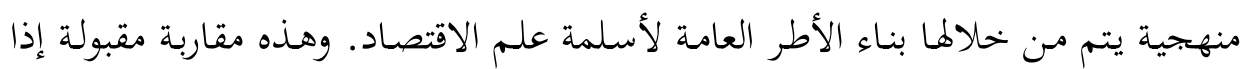

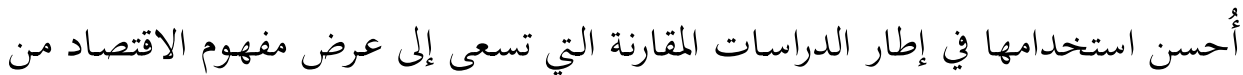

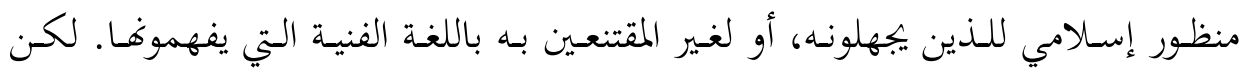

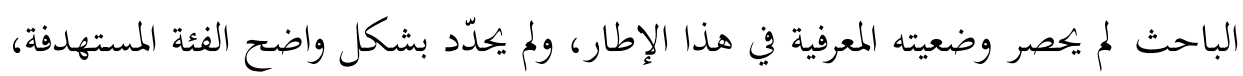

rrr الزرقا، أنس. "تحقيق إسلامية علم الاقتصاد: المفهوم والمنهج"، مجلـة جامعة الملك عبدل العزيز : الاقتصـاد 


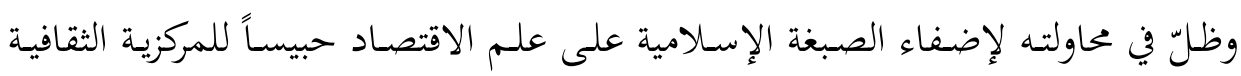
الأوروبية التي تجعل الثقافات الأخرى تابعة لها.

\section{r. الملم الاقتصاد الإسلامي: ماذا يجب أن يكون:}

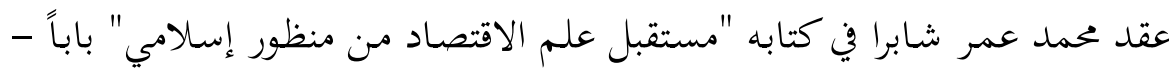

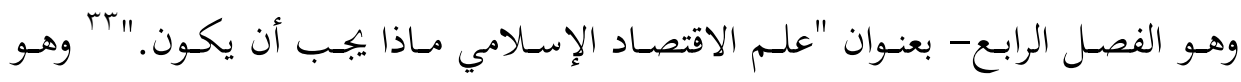
يتلخص في فكرة مؤداها أنه في الوقت الذي يقتصر فيه الاقتصاد السائد على مناقشة ما الإنا

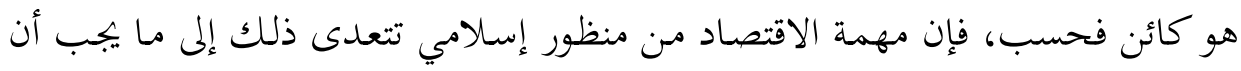

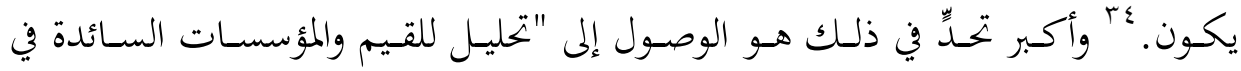

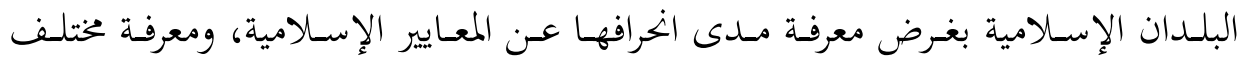

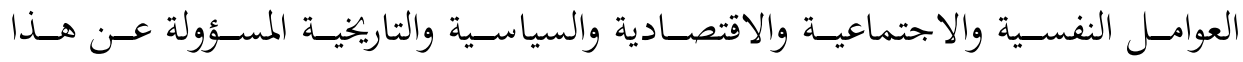

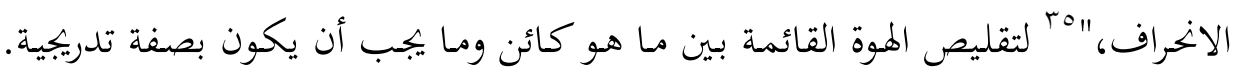

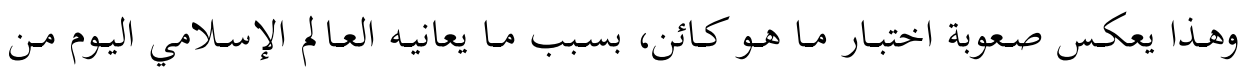

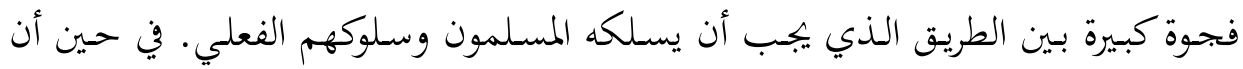

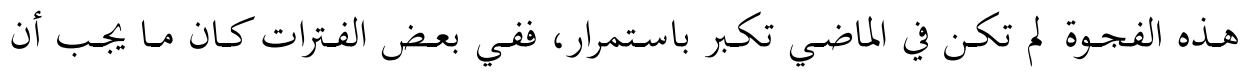

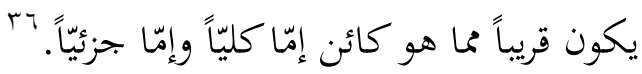
ومن خلال هذا الطرح يتضح ما يلي:

• ليس المقصود من عنوان الفصل بأن الاقتصاد الإسلامي اقتصاد معياريّ فحسب، بل تأكيد أنه يجمع بين المقاربتين: الوضعية والمعيارية. • الاقتصاد الإسلامي يتميّز عن الاقتصاد التقليدي بالمقاربة المعيارية. rr شابرا، حمد عمر . مستقبل علم الاقتصاد من منظور إسلامي، ترجمة: رفيق المصري، دمشق-بيروت: دار الفكر،

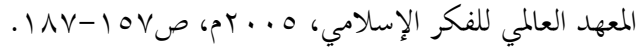

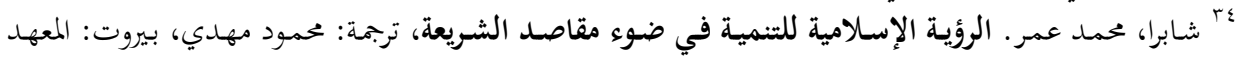

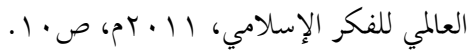

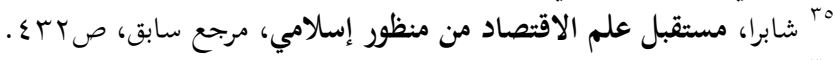

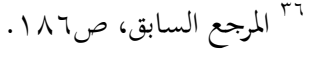




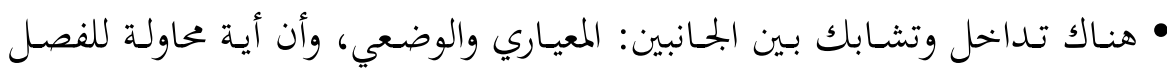
بينهما قد تكون مضللة وغير بحدية.

انطلاقًا من قطبي الوضعية والمعيارية، يبقى طرح مستقبل علم الاقتصاد من منظور

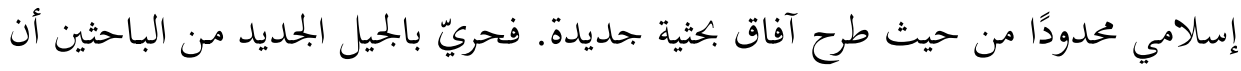

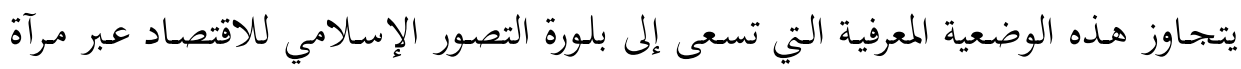

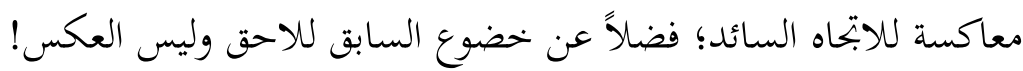

\section{ع ـ الاقتصاد الإسلامي بوصفه مذهباً ونظاماً يدرس ما يجب أن يكون:}

يرى محمد شوقي الفنجري في كتابه "الوجيز في الاقتصاد الإسلامي" أن "الدراسات

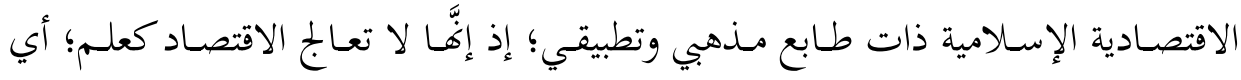

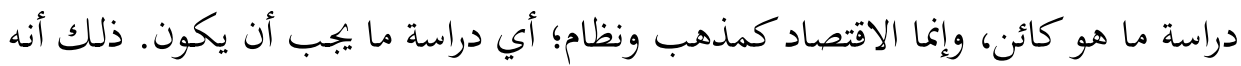

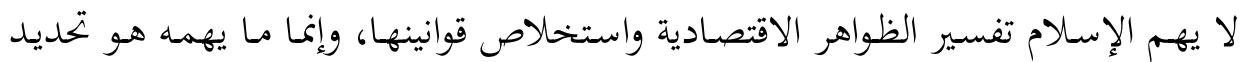

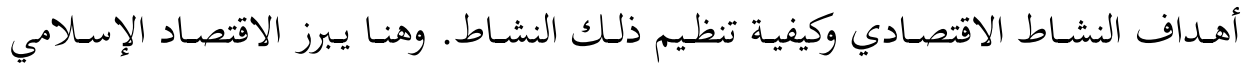

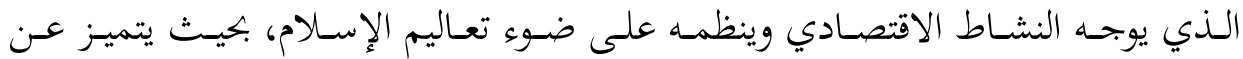

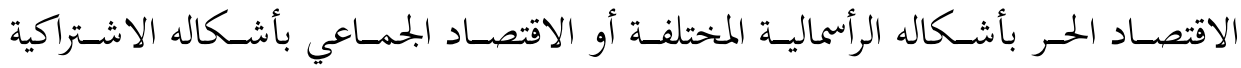

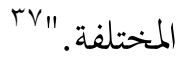

ويضيف الباحث قائلاً: إن "علم الاقتصاد محايد وليس بعامل مميز يستقل أو ينفرد

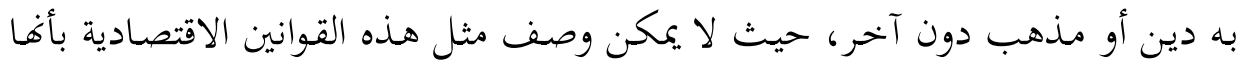

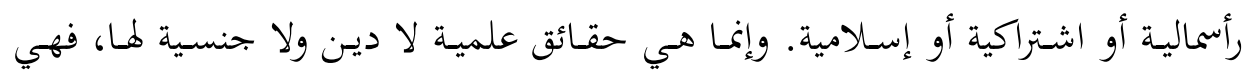

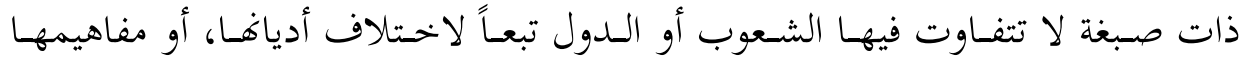

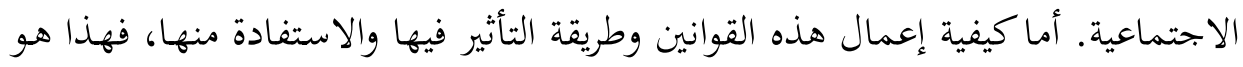

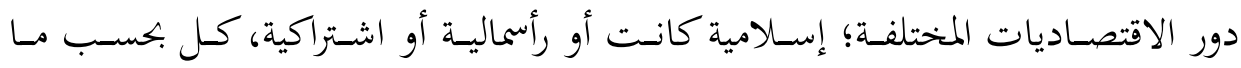

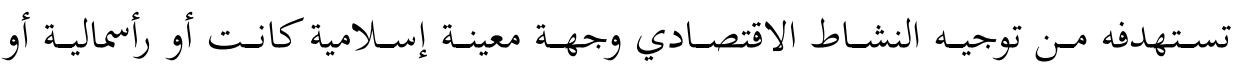

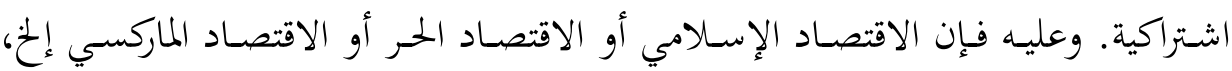

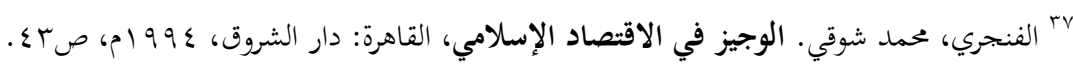




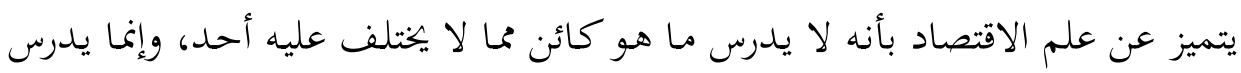

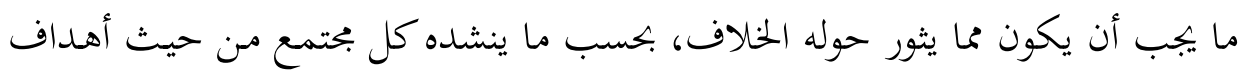

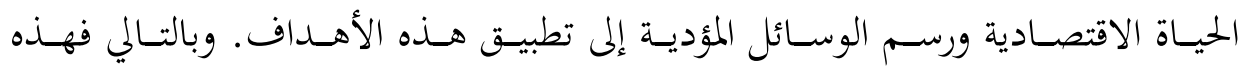

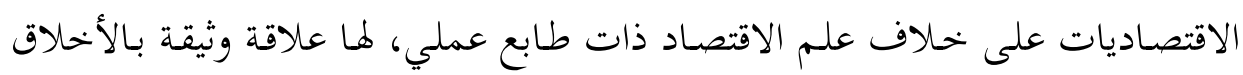

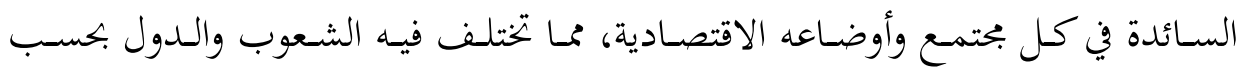

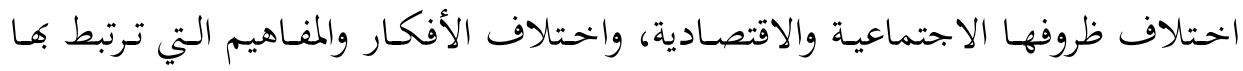

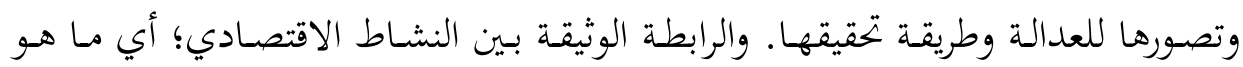

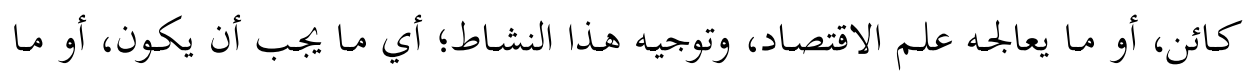

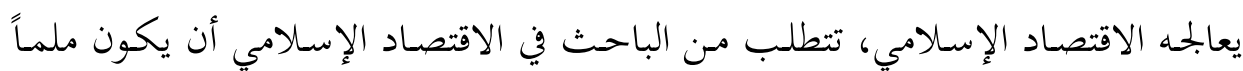

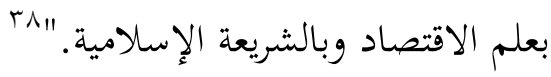

من هنا يتضح أن الباحث يستخدم المقاربتين: الوضعية والمعيارية لتأكيد أن:

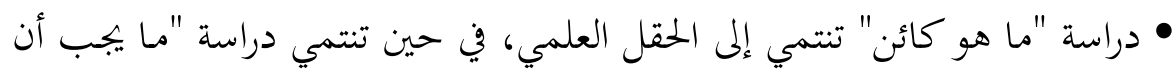
يكون" إلى حقلي المذهب والنظام الاقتصادي.

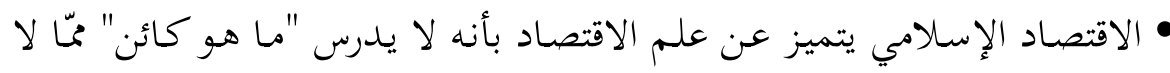

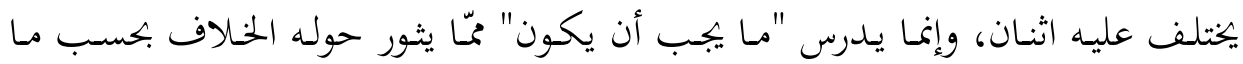

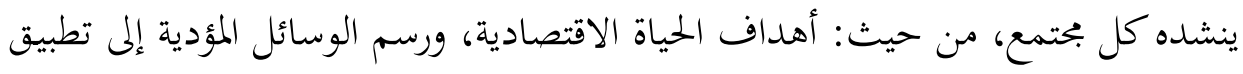

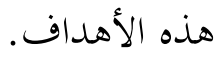

هالاقتصاد الإسلامي يتميز عن غيره من المذاهب والنظم الاقتصادية في توجيهه النشاط الاقتصادي وتنظيمه على ضوء تعاليم الإسلام.

ه. بين ما هو كائن، وما ينبغي أن يكون، وما يجب أو ما كان يجب أن يكون: يقول حسين غانم في كتابه "الاقتصاد الإسلامي طبيعته وبحالاته": "يفرق العلماء بين

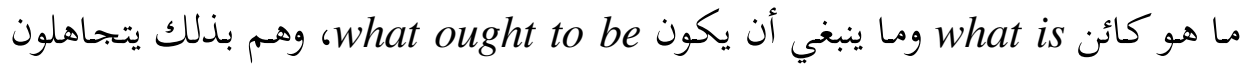




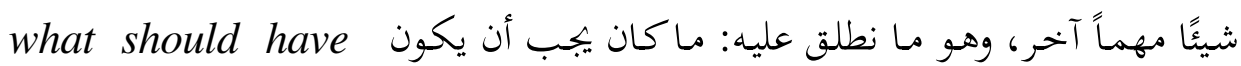
[.... [ been

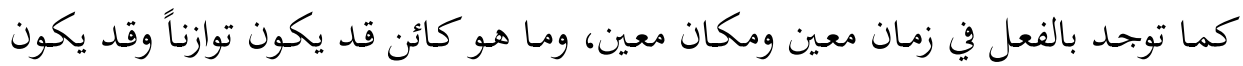

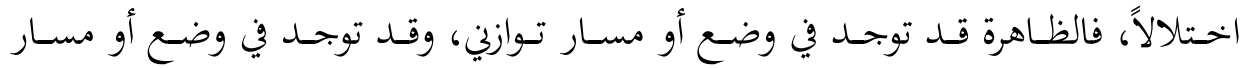
اختلالي [...] ونعبر عن الوضع أو المسار التوازي للظاهرة - أي النموذج المرجعي - بأنه

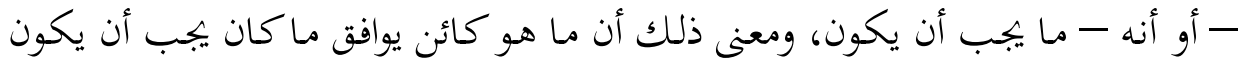

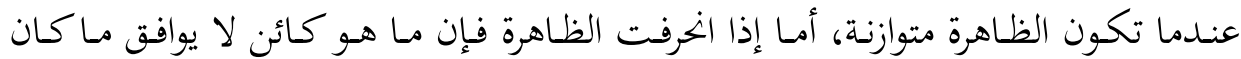

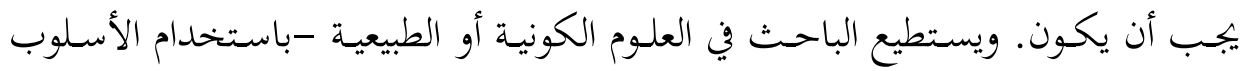
الاستقرائي، الذي يعتمد على دراسة ما هو كائن - أن يتوصل إلى النموذج المرجعي للظاهرة

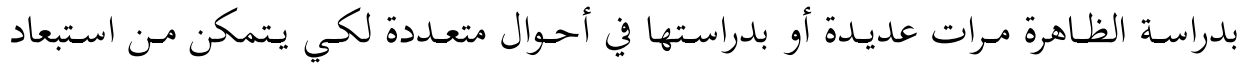

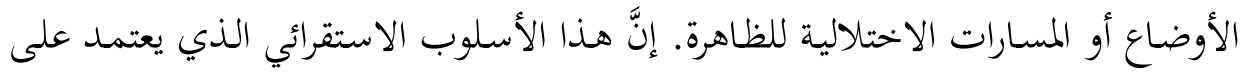
دراسـة الظـاهرة اللإراديـة - كمـا هي - لا يصـلح في دراسـة الظـاهرة الإراديـة؛ أي الحركـة الإراديـة للإنسـان، لسـبب واضـح وهـو أنَّ الإنسـان لا يخضـع في حركتهـ الإراديـة لقـوانين

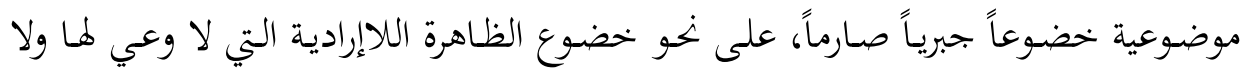

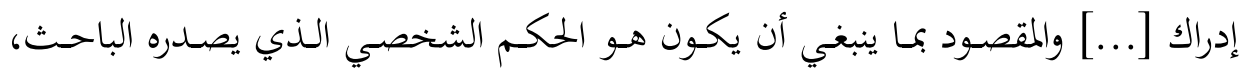

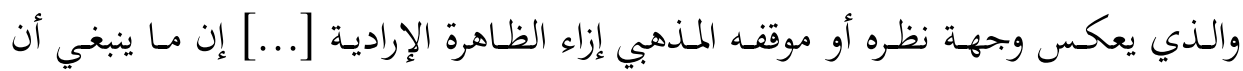

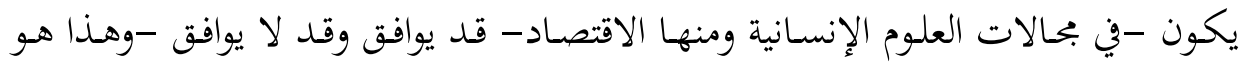

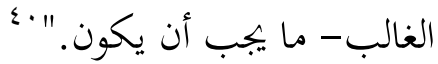

ويهدف الباحثث من خهلال استخدامه المقاربتين: الوضعية والمعيارية إلى توضيح ما يأني :

• ضرورة التغريق بين "ما هو كائن"، و "ما ينبغي أن يكون"، و "ما يجب أو ماكان يجب

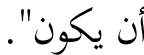

9ar الظاهرة الإرادية هنا هي الحركة التي تخص الإنسان بوصفه مكلفاً، والظاهرة اللاإرادية هي الحركة اللاإرادية التي تخص الطبيعة أو الكون.

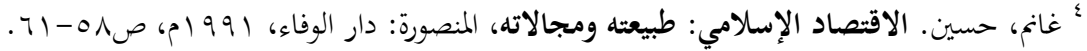




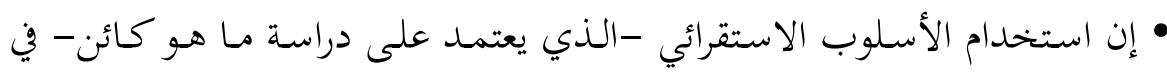

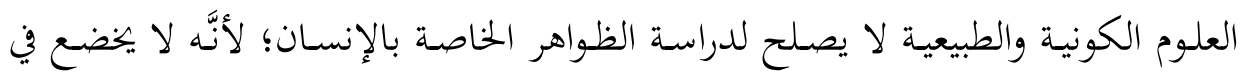

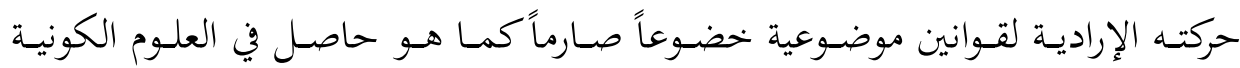
والطبيعية.

• المقصود بما ينبغي أن يكون هو الحكم الشخصي الذي يصدره الباحث، ويعكس وجهة نظره أو موقفه المذهبي. • إن قواعد الإسلام وأحكامه ليست من قبيل "ما ينبغي أن يكون"، وإنما هي من ئن قبيل "ما يجب أو ما كان يجب أن يكون". • إن "ما هو كائن" يوافق "ما كان يجب أن يكون" عندما تكون الظاهرة متوازنة،

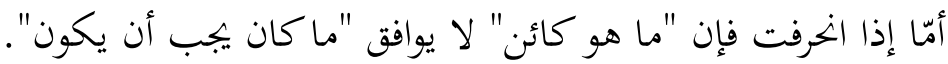
• إن "ما ينبغي أن يكون" في الاقتصاد قد يتفق وقد يتعارض وهو الأكثر شيوعاً

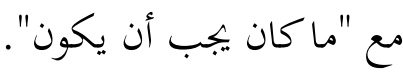

\section{7. بين ابن تيمية الفقيه وابن خلدون الاقتصادي:}

ألقـى عمـاد الـدين أحمــ محاضـرة في النـدوة التي نظمتهـا الجمعيـة الفرنسـية الليبراليـة

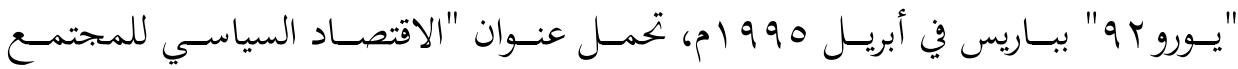

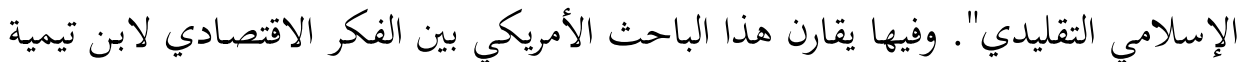

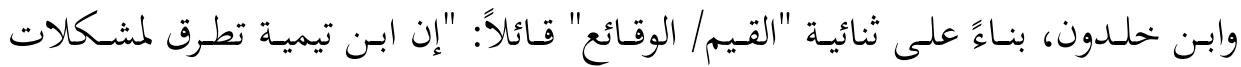

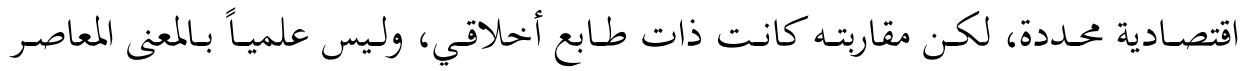

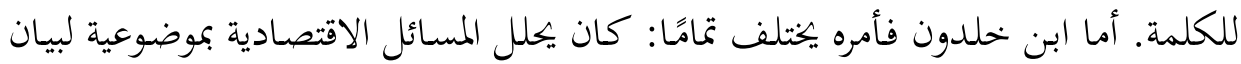

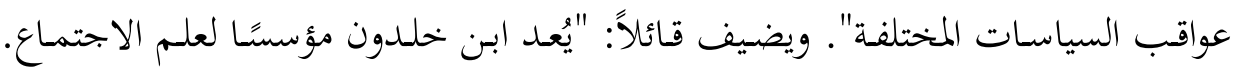

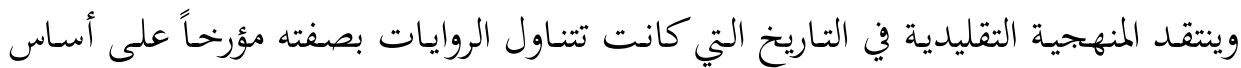

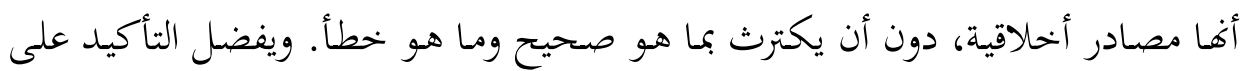

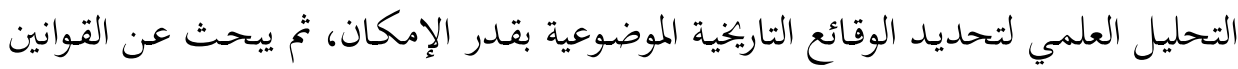


الاجتماعية التي يُحتمل أن تكشف عنها مسيرة التاريخ. وعلى خلاف ابن تيمية الذي يقرر

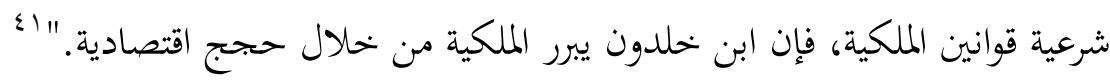
وبهذا يتم استخدام ثنائية "معياري/ وضعي" في تصنيف كتابات الفقهاء إلى ما هو علمي وما هو غير علمي، بالمفهوم المعاصر الضيق للكلمة السائد في فترة الحداثة؛ إذ تم إقصاء الدين على شكل لعبة معرفية صفرية. أمّا الدراسات الإبستمولوجية لمرحلة ما بعد

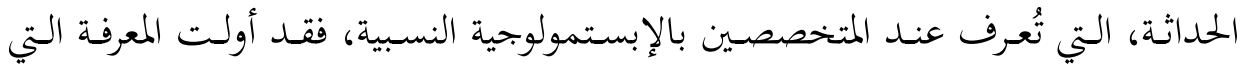

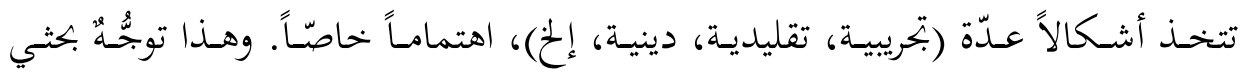
جديد خَفِيَ على الباحث، أو ربما بتحاهله

\section{V. إسهام الاقتصاد الإسلامي في تنشيط الفرع المعياري للاقتصاد السياسي:}

يرى الاقتصادي الألماني فولكر نينهاوس أن الاقتصاد الإسلامي قد يُسهم في تنشيط الفـرع المعيـاري للاقتصـاد السياسي، ومسن ثم قــ يُسـهم في تحقيـق المصـالحة بـين المقاربـة

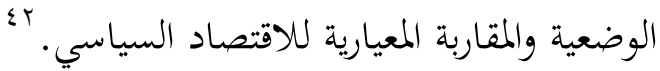

يتضح مّّا سبق أن مغزى اهتمام الباحث بالاقتصاد الإسلامي هو معرفي بحت، يتلخص

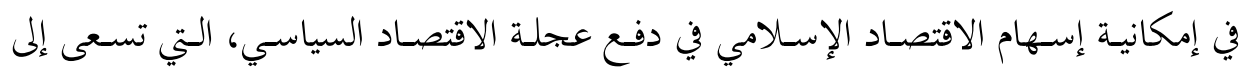
تقليل الهوة بين المقاربة الوضعية والمقاربة المعيارية. ولا يمكن للاقتصاد الإسلامي أن يحقق ذلك إلا إذا شكّل هوية خاصة به تميزه من غيره، وتفتح آفاقًا بحثية جديدة، وتدفع إلى بتديد دور المعايير والقيم في السلوك الفردي والسياسة الاقتصادية. وهذه الخلفية المعرفية توضح فحوى كلامه في إحدى الندوات، حين صرح بأنه من الضروري للتمويل الإسلامي أن يظل مرتبطاً

${ }^{41}$ Ahmed, Dean. L'économie politique dans la société islamique classique, Colloque "Islam et Libéralisme" à l'Institut Euro92, Paris: avril 1995, p. 21.

${ }^{42}$ Nienhauss, Volker. Epistemology, Methodology and Economic Policy: some Thoughts on Mainstream Austrian and Islamic Economics, Humannomics, Vol.5, Issue1, 1989, pp. 91-112. 
بالاقتصاد الإسلامي، ومستنده المعريف القائم على نظرة معينة للكون والإنسان ووظيفته في

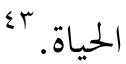

وهنـا يُطـرح تسـاؤل عـن ثقــل البُعـــ المعيـاري والبُعـد الوضـعي في العمليـة المعرفيـة

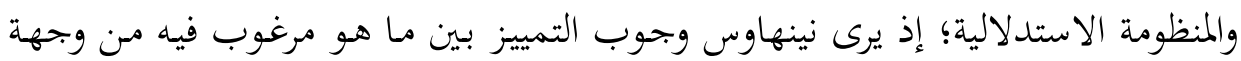

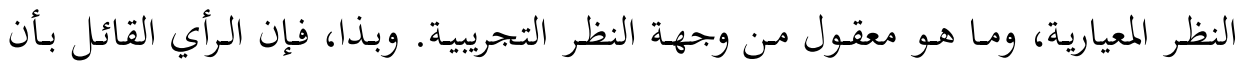

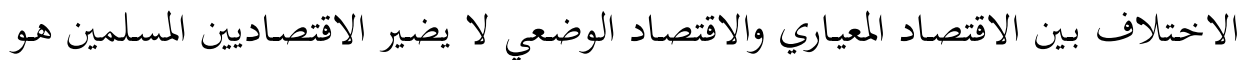

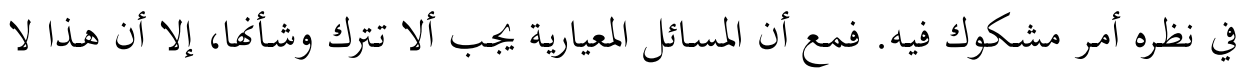

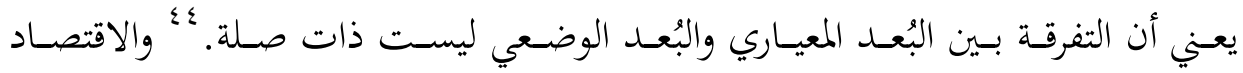

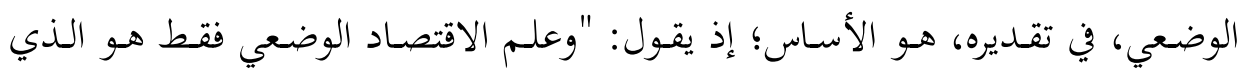

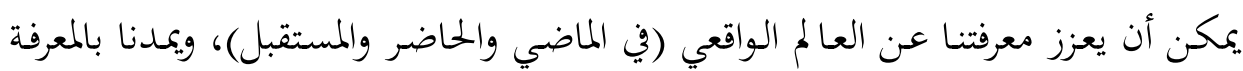

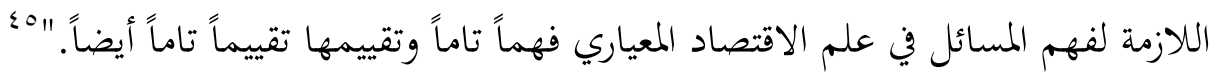

\section{^. تراث الاقتصاد الإسلامي بين كتب الشريعة وكتب الفِكر :}

ألّف رفعت العوضي كتابًا عنوانه "تراث المسلمين العلمي في الاقتصاد (المساهمة العربية

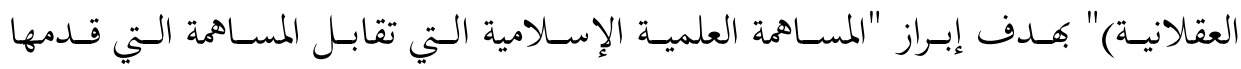

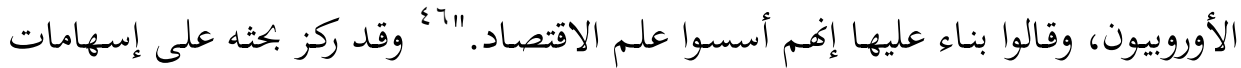

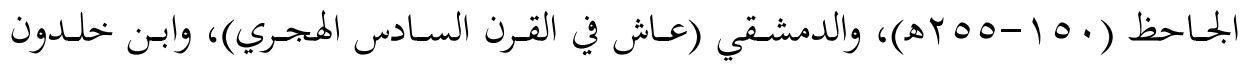

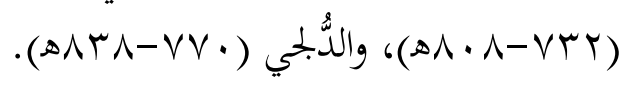

${ }^{43}$ Nienhaus, Volker. Challenges and Initiatives of Human Capital Development Through Islamic Finance, Communication presented at the Forum: Human Capital Development for Islamic Financial Industry: Challenges and Initiatives, organized by The Islamic Research Training Institute and The General Council of Islamic Banks and Financial Institutions, Jeddah: Hilton Hotel, June 1, 2008.

“نينهاوس، فولكر . "آراء جديدة في علم الاقتصاد المعياري النهوج الغربية والمنظور الإسلامي"، مجلة المسلم

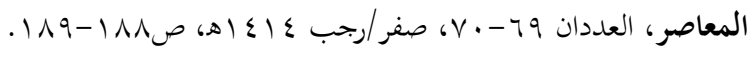

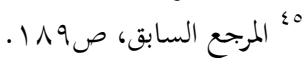

تـ العوضي، رفعـت. تراث المسـلمين في الاقتصـاد (المسـاهمة العربيـة العقلانيـة)، القـاهرة: مركز صـالح كامـل 
بنـاءً على هـذا المنطلق، يقـول الباحـث: "نسـتطيع أن نتقـدم في تبريـر المـنهج الذي

قصرنا بموجبه دراستنا على التراث الذي يعرض الفكر الاقتصادي كتحليل عقلي: • كتب الشريعة تبحث عن اقتصاد مُؤسَس على الآتي: يجب أن يكون.

• كتـب الفكـر المؤسَسـة على التحليـل العقلي، يتأسس البحـث فيها على الآتي: تفسير مـا هـو كائن. ونستهدف في دراستنا عرض تراث المسلمين العلمي في الاقتصاد

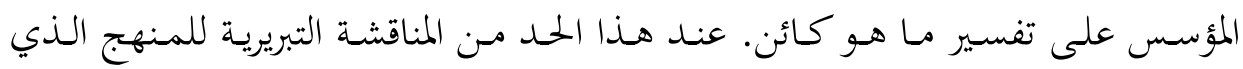

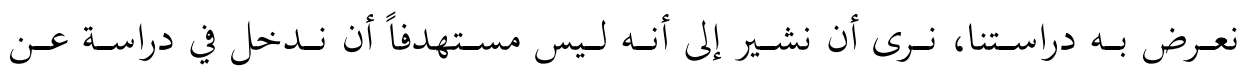

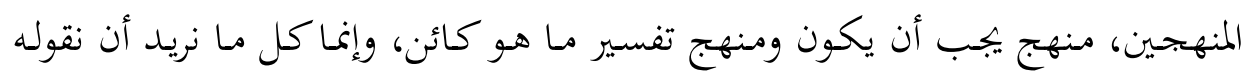

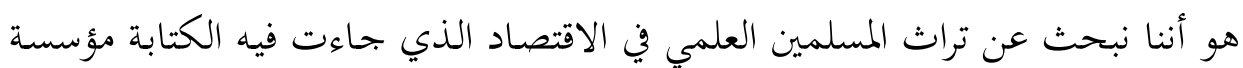

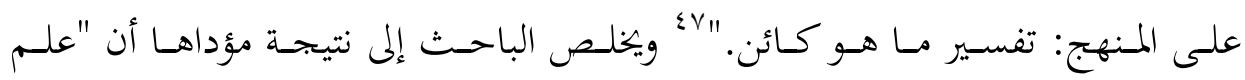
الاقتصـاد تأسس في إطار تراث المسـمين العلمي في الاقتصـاد، بينمـا يعتقـد الأوروبيون

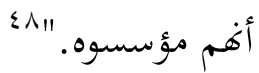

ويسـتخدم الباحـث ثنائيسة "مـا هـو كـائن/ مـا يجــب أن يكــون" لتقسـيم الـتراث

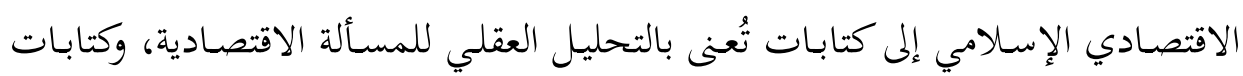

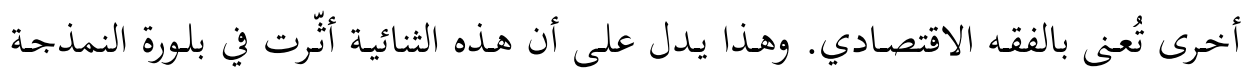
المالائمة لتصنيف التراث الاقتصادي الإسلامي.

9 ـ بين المقاربة المعيارية والمثالية التي يرتكز عليها نموذج الاقتصاد الوضعي

\section{السائد:}

يقول محمود أبو السعود في كتابه "فقه الزكاة المعاصر": "ليس هنـاك تعريف متفق عليه لعلم الاقتصاد؛ إذ هو علم حديث بالنسبة للعلوم الأخرى [...] وإذ يتجنب علماء المعاء الاقتصاد وضع تعريف مانع جامع، يفضلون تقسيم هذا العلم إلى ما يسمونه الاقتصاد

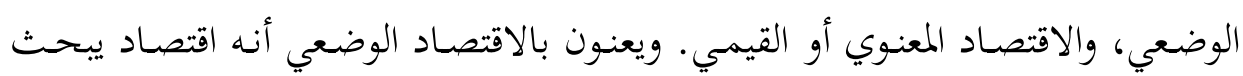




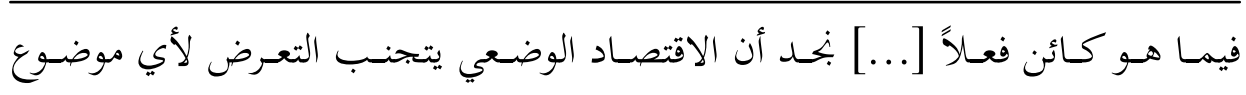

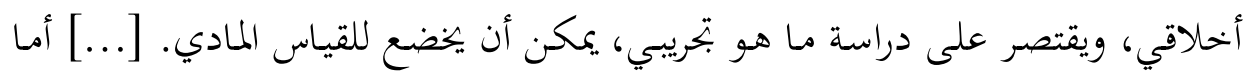

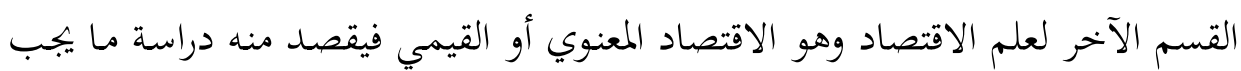

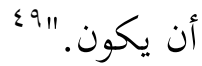

وهكـا يستخدم الباحـث تقسيم "اقتصـاد وضعي/ اقتصاد معيـاري" خـارج إطـار الاقتصاد الإسلامي لنقد الاقتصاد التقليدي من أوجهد عدة:

• اتخاذ الاقتصاديين هذا التقسيم طريقة لتجنب وضع تعريف مانع جامع لعلم الاقتصاد.

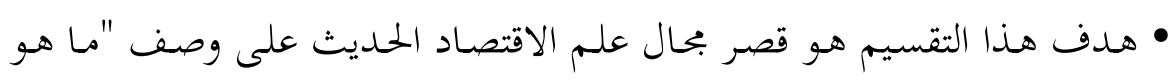

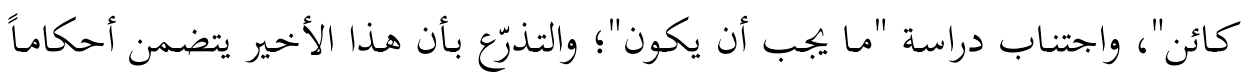
قيمية، وهي بهكم طبيعتها غير موضوعية.

• قصر علم الاقتصاد على وصف "ما هو كائن" يؤكد الانحياز للمذهب الوضعي. • تعبير هذا القصر عمّا وصل إليه علم الاقتصاد من تردّ وتخلف مهيمن؛ إذ إذ أصبح

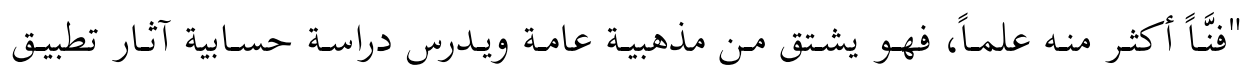
مبادئه على بجتمع شديد التعقيد."

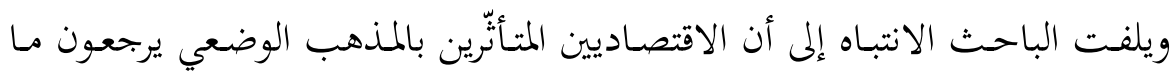

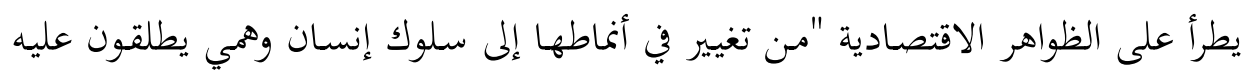

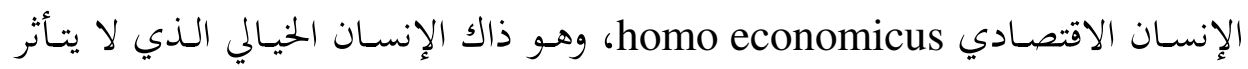

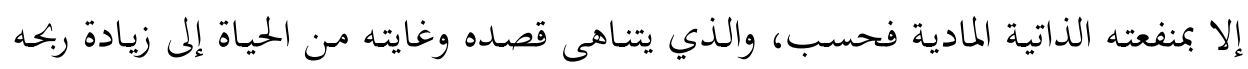

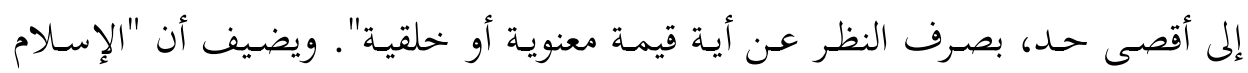

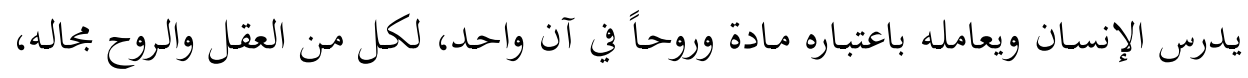

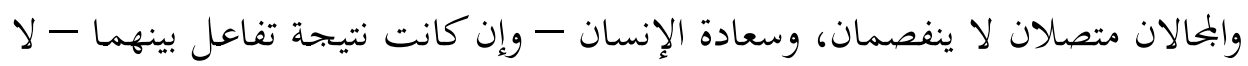

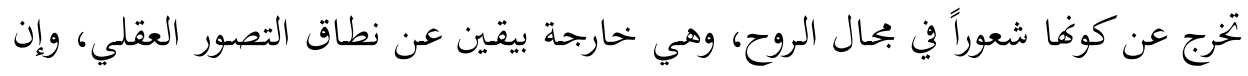

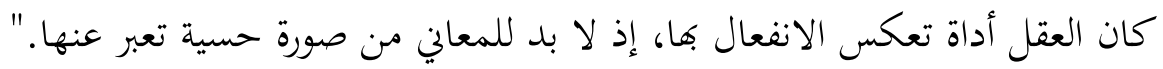


يتطرق الباحث أيضاً إلى مسألة منهجية جوهرية تتمثّل في ضرورة التفريق بين المقاربة المعيارية بوصفها طريقة تحليلية يرتكز عليها نموذج الاقتصاد الوصفي السائد، الذي يدرس في كليـات الاقتصـاد؛ إذ يقـول: "فهـل يجـوز لنـا أن نلـوم الاقتصـاديين على إغفـالهم القيم

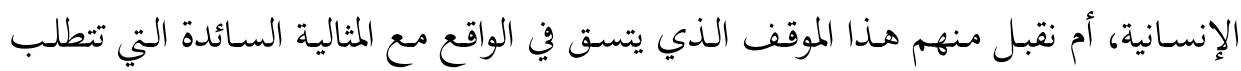
منهم هذا الإغفال؟ إن كان هناك لوم، فليوجه إلى المثالية وليس إلى الاقتصاد الوصفي. وإن كان هناك فرق بين الاقتصاد الإسلامي وغيره مـن ضروب الاقتصاديات، فذاك هو الفرق

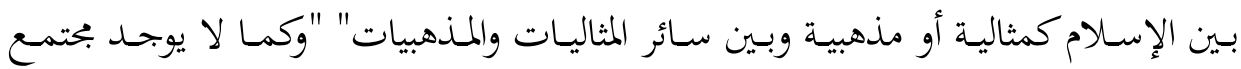
إسلامي دون اقتصاد إسلامي، فكذلك لا يوجد اقتصاد إسلامي دون بحتمع إسلامي."

\section{• 1 . عدم الاكتفاء بالتجربة شرطاً وحيداً لبناء نظرية الاقتصاد الإسلامي:}

في مقالـة عنوافها "الاقتصـاد الإسـلامي : فلسفتهه ومنهجـهـ العلمي"، يستخدم عبــ

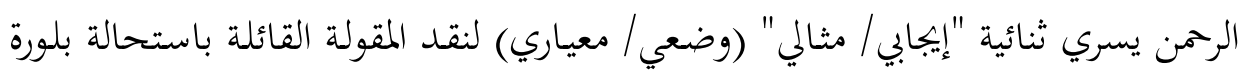
نظرية اقتصادية إسلامية قبل بناء نظام اقتصادي إسلامي متكامل على المستويين: الجزئي

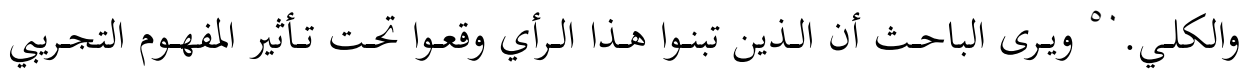
للعلم واستبعدوا تماماً المفهوم المثالي. ففي الوقت الذي لا يمكن فيه بتحاهل البُعد التجريبي

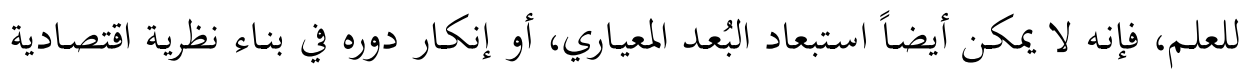

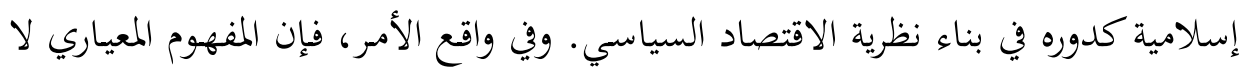
بدّ أن يكون له دور رائد في بناء نظرية الاقتصاد الإسلامي، وخحاصة في مرحلة التميّز عن ونسي

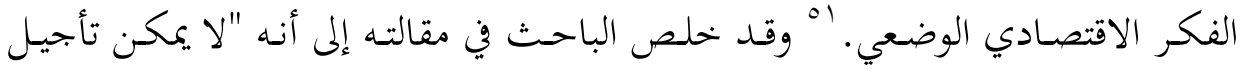

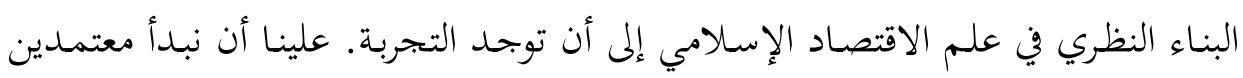

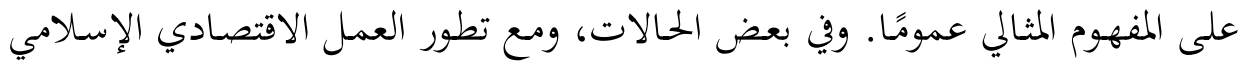

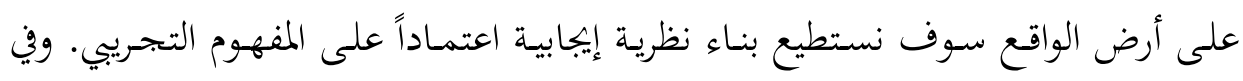

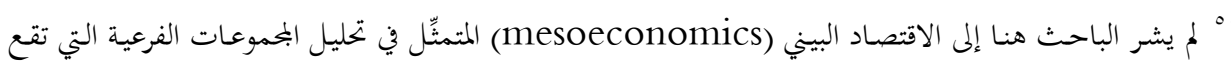

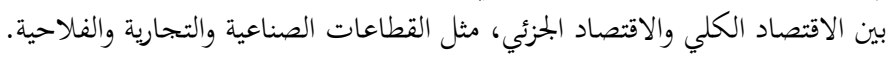

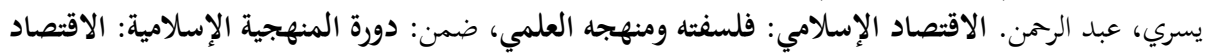

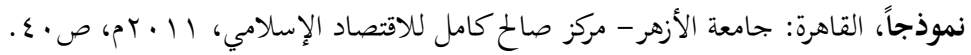




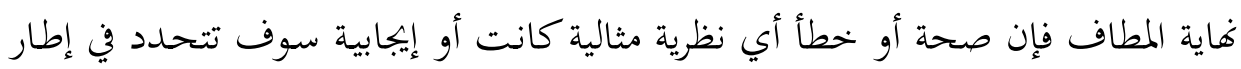

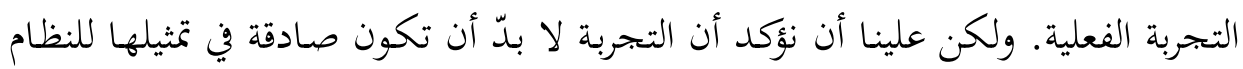

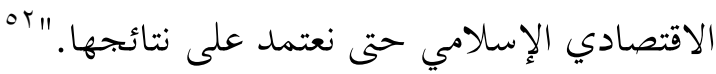
خلافاً لما هو معتاد، يستخدم الباحث ثنائية "وضعي / معياري" لنقد مقولة طرحها بعض الذين كتبوا عن الاقتصاد الإسلامي، وفي مقدمتهم محمد باقر الصدر حين قال:

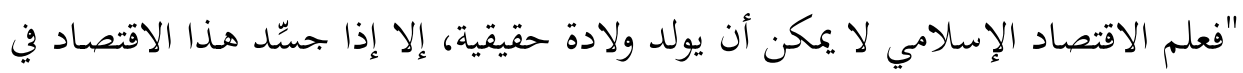

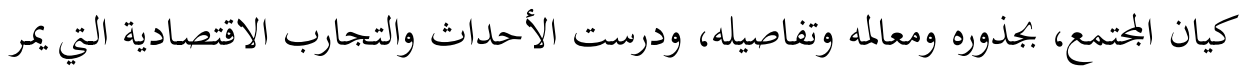

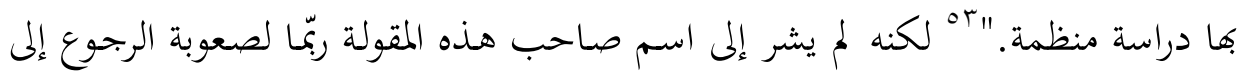
موضعها في الكتاب أو لسبب آخر.

\section{1. نطاق علم الاقتصاد الإسلامي ومجالات البحث فيه:}

في مقالة عنواها "نو منهجية للبحث الاقتصادي الإسلامي"، يشير شوقي دنيا إلى

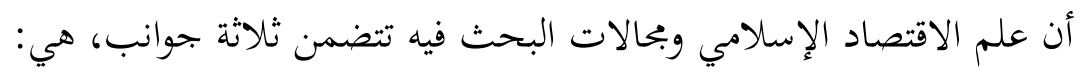
أولاً: دراسة السلوك الاقتصادي من حيث ما هو كائن، وتتمثّل في وصفه وتفسيره

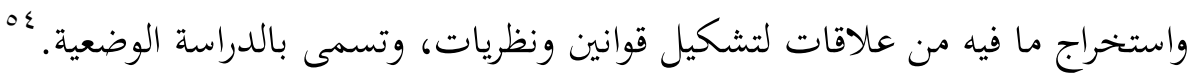
ثانياً: دراسة السلوك الاقتصادي من حيث منطلقاته ومسلّماته ومرتكزاته وما وراءه

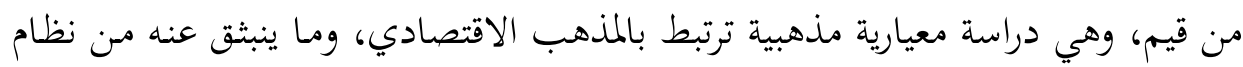
أو أنظمة. ثالثـاً: دراسـة السلوك الاقتصـادي مـن حيـث مـا ينبغي أن يكـون، وهي أيضـاً في

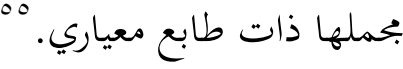

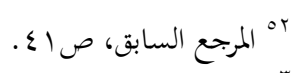

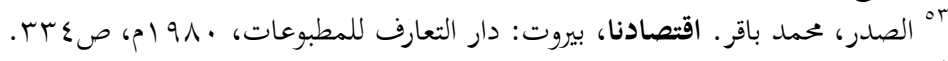

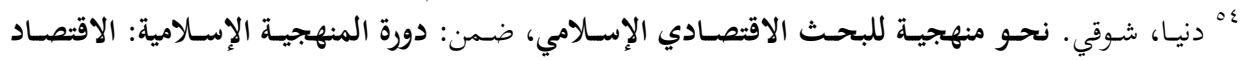

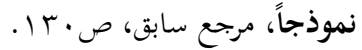

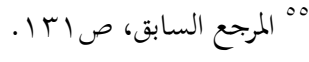


وبهـذه الطريقــة يسـتخدم الباحـث ثنائيـة "وضـعي/ معيـاري" لبيـان أن نطـاق علـم الاقتصاد الإسـلامي يتسع لبحثث مقولاته المذهبية والنظامية والنظرية والسياسية، بخلفية

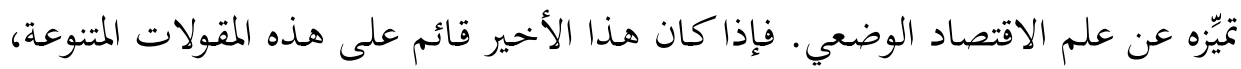

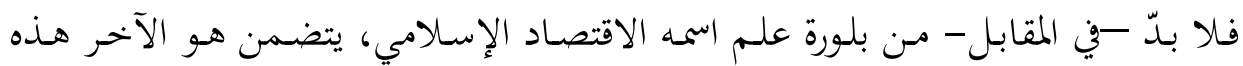
الأبعاد المختلفة.

وقد تبادر إلى ذهن الباحث أسئلة عدّة، من مثل: ما الذي ينبغي فعله للعلم القائم

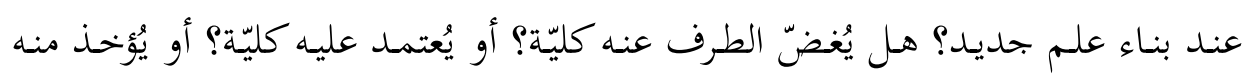

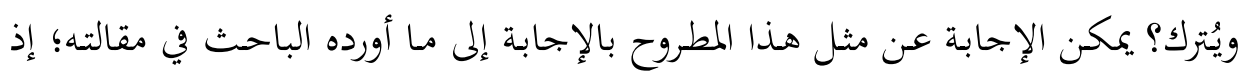

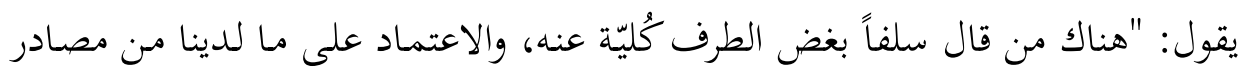
نقلية وعقلية، من منطلق أننا نريد بناء البديل، ومن ثم لا بحال للاعتماد على المبدل منهـ منه

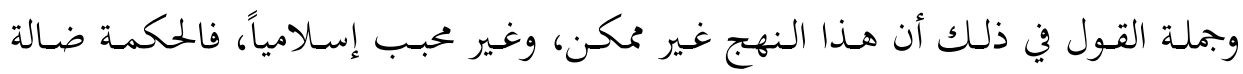

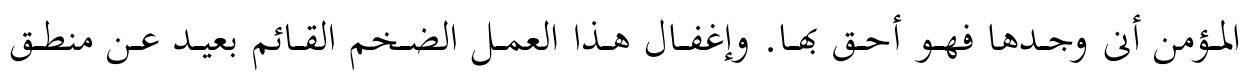

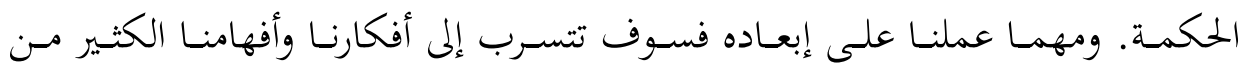
مقولاته.

وهناك من قال بالثاني، على أساس أن ننقيه مما به من شوائب ومخالفات، وما يتبقى

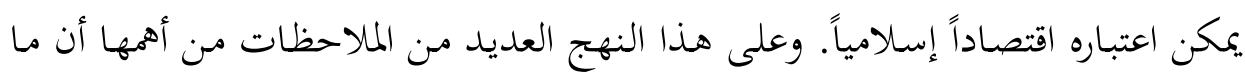

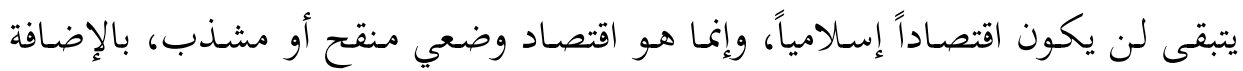
إلى صعوبة عملية التشذيب هذه من الناحية العملية [...].

وإذن لا يبقى إلا النهج الثالث، وهـو أن نستفيد منه بمـا يمكـن الاستفادة بـه مـن

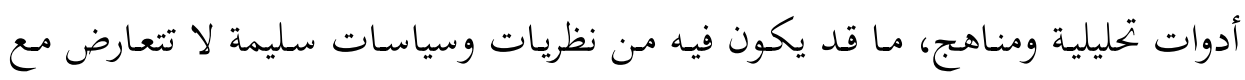
الهدي الإسلامي في هذا البحال. مع ضرورة الوعي التام بالظروف التي نشأ فيها التحليل

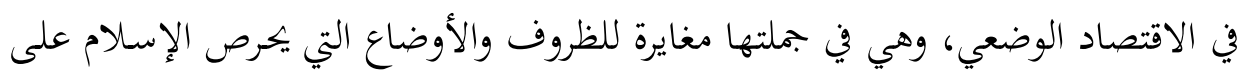

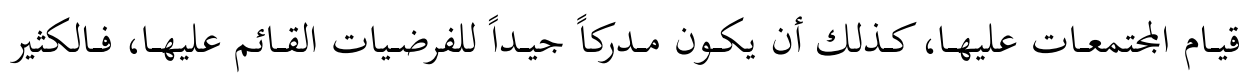




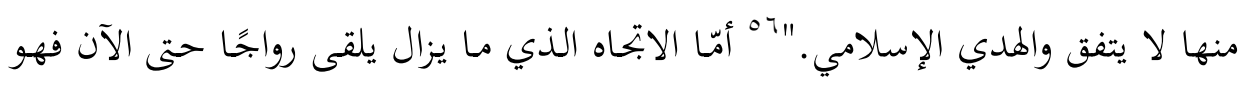

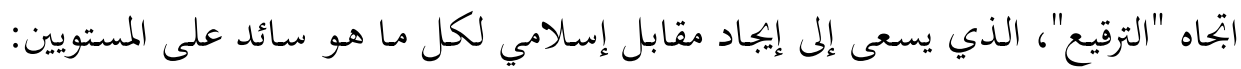

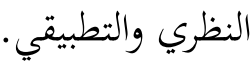

\section{r I ا. بين الإعجاز العلمي والإعجاز التشريعي في الاقتصاد:}

يستخدم رفيق المصري الثنائية لنقد القائلين بأن علم الاقتصاد علم محايد، لا يبحث

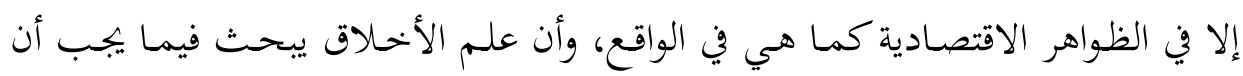

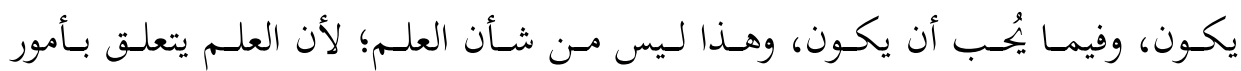

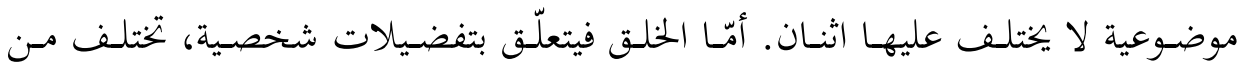

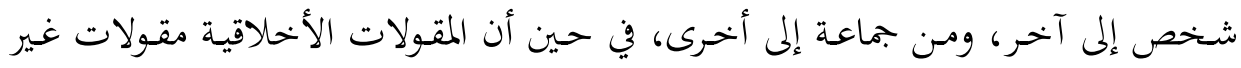

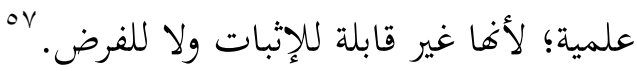

ويشـير الباحـث إلى بعض الاقتصـاديين الغربيين الـذين لا يفصلون الاقتصـاد عـن

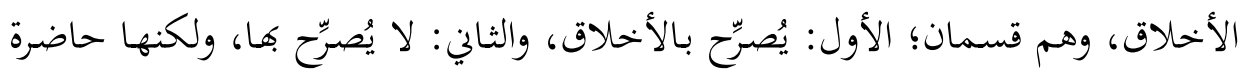

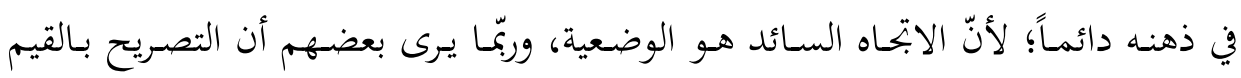

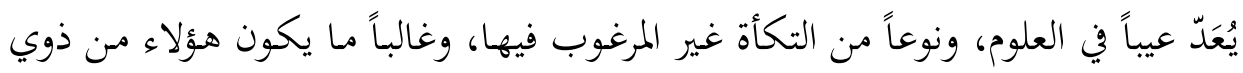

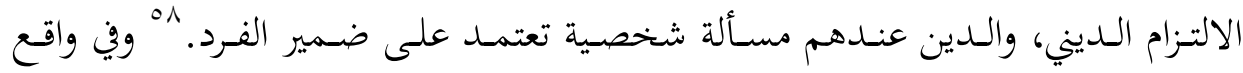

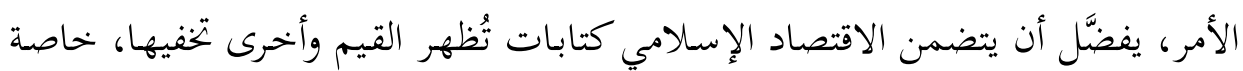

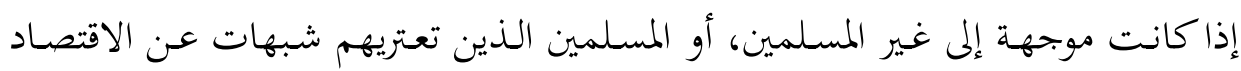

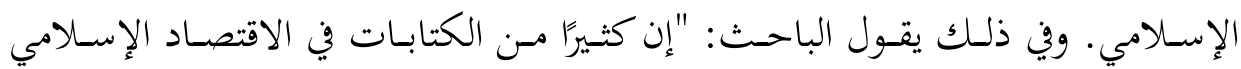

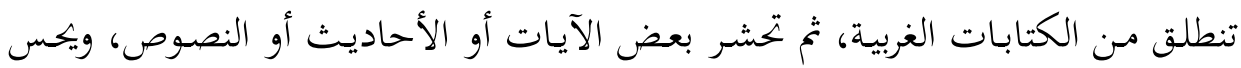

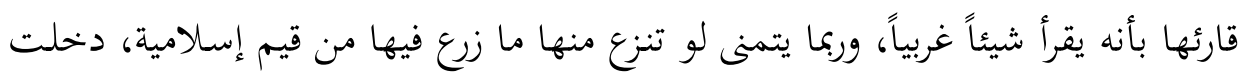

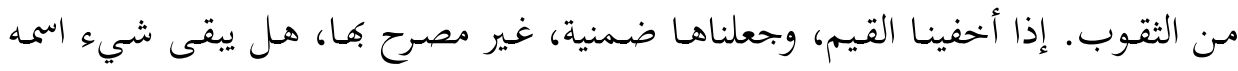

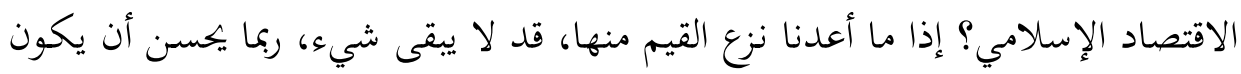

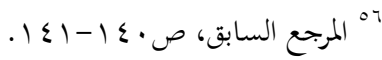

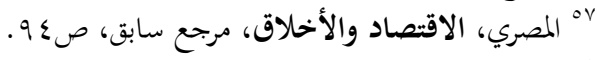

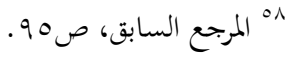




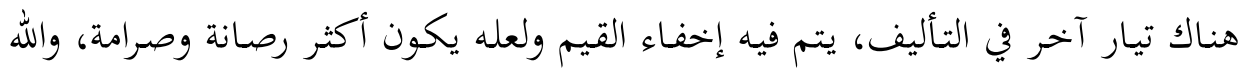

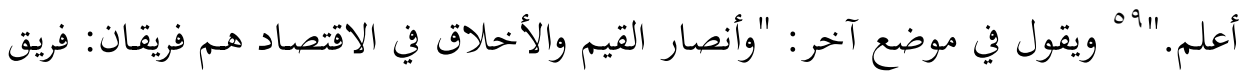

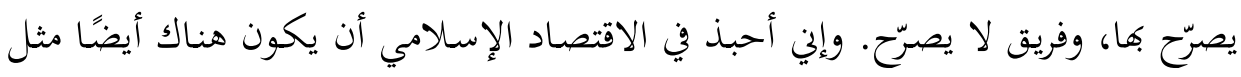

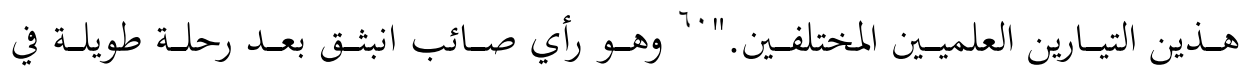
الاقتصاد الإسلامي.

من جهة أخرى، يرى الباحث أن المعيارية لا تتنافى مع الوضعية، بل تضيف إليها

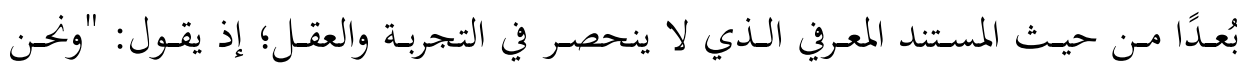

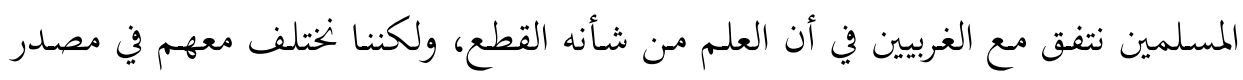

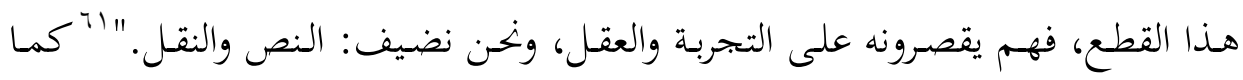

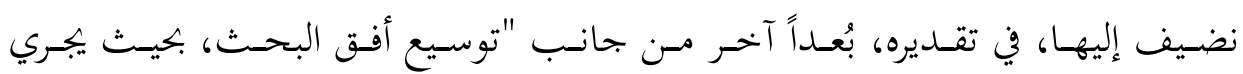

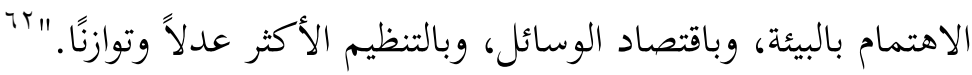

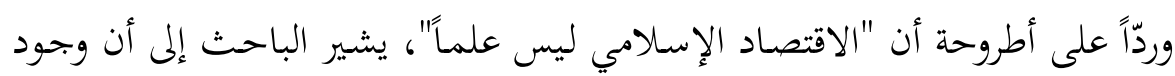

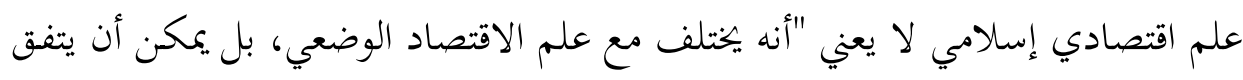

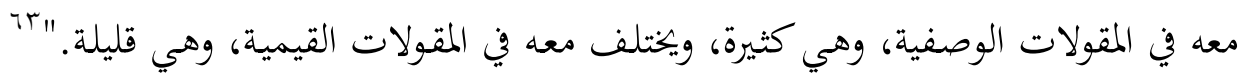

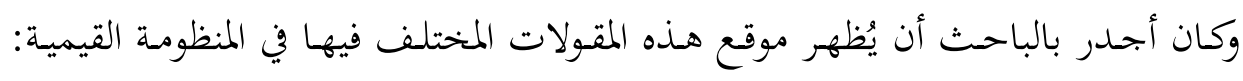

$$
\text { هل هي أساسية أو تابعة؟ آلمان }
$$

وفي ظـل الاهتمـام المتزايـــ بيُعـــ الاقتصـاد المعيـاري، يــى الباحـث أن الاقتصـاد

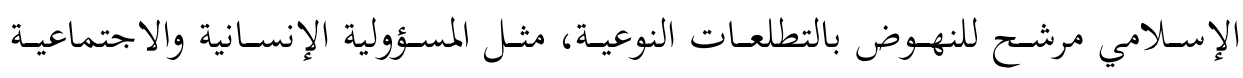
9๑ المصري، رفيق يونس. القيم في الاقتصاد بين الإظهار والإنفاء، ضمن: حوار الأربعاء خلال الأعوام الدراسية

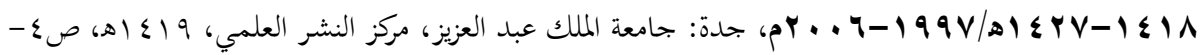

$$
\text { "ا" المصري، الاقتصاد والأخلاق، مرجع سابق، صا. }
$$

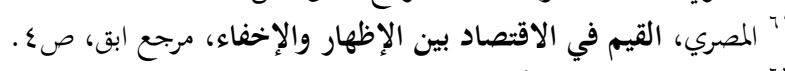

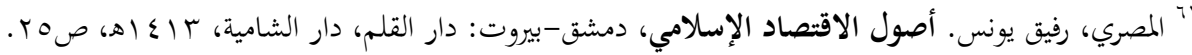

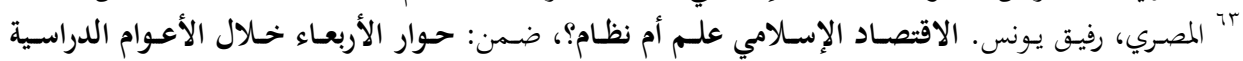

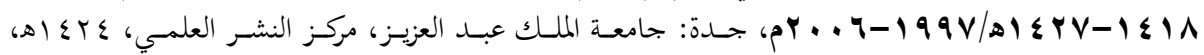




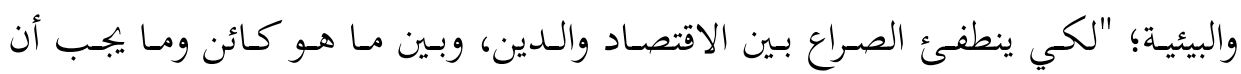

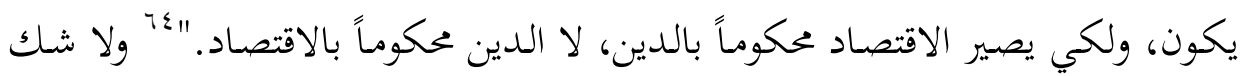

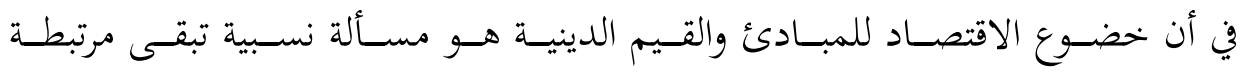

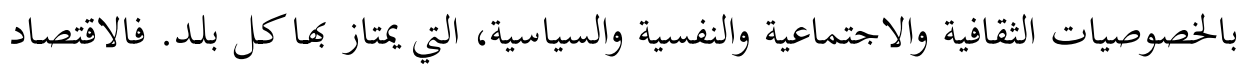

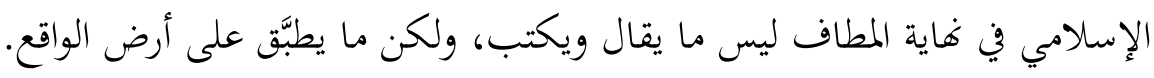
وفي معرض حديثه عن جلاء الأخلاق في الاقتصاد، يرى الباحث أن طرح المشكلة مسألة وضعية. أما حل المشكلة فهو مسألة تدخلها الأخحلاق.

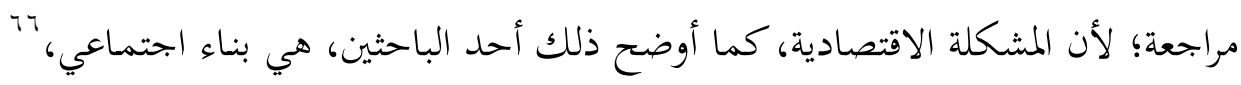

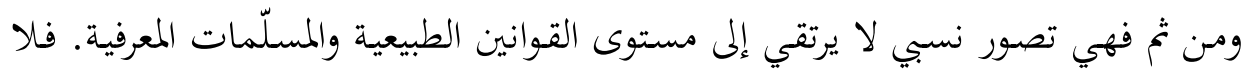

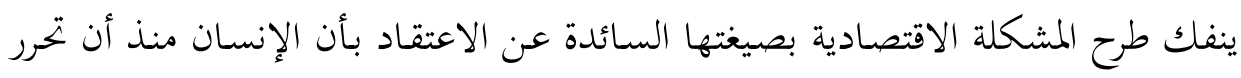

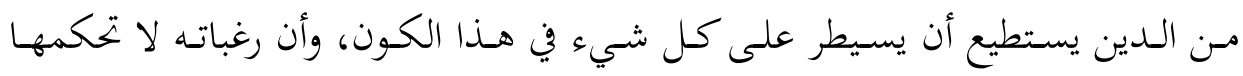

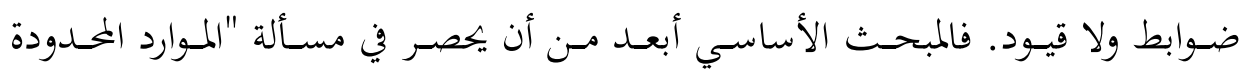

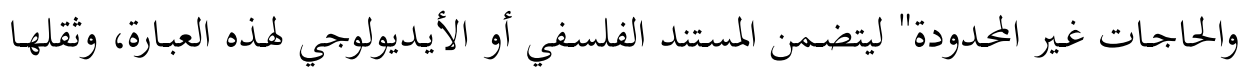

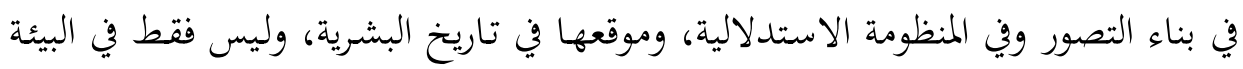
الأوروبية التي نشأت فيها كأنها آخر ما يمكن التوصل إليه!

ومن آثار ثنائية "معياري/ وضعي"، تفرقة الباحث بين الإعجاز التشريعي والإعجاز

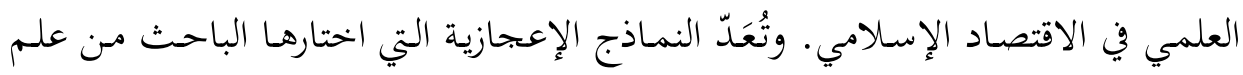

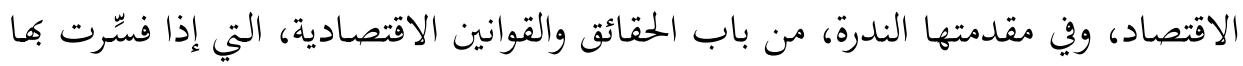

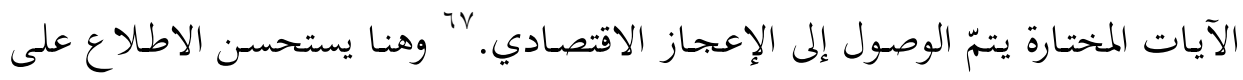

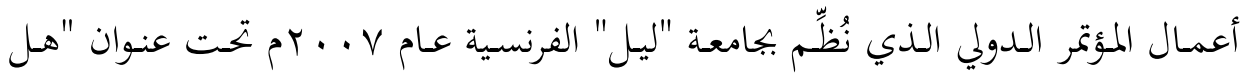

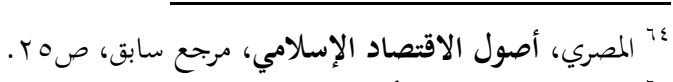

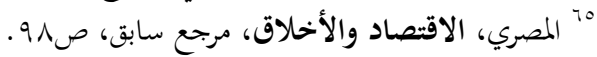

${ }^{66}$ Ventelou, Bruno. Au-delà de la rareté. La croissance économique comme construction sociale, Paris: Albin Michel, 2001. 
يوجد قوانين في الاقتصاد؟"، وتُوصِّل فيه إلى خلاصة مؤداها أن الاقتصاد لا يملك قوانين

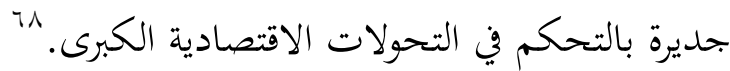

خاتمة:

سعت هذه الدراسة إلى تسليط الضوء على استخدامات ثنائية "وضعي/ معياري"

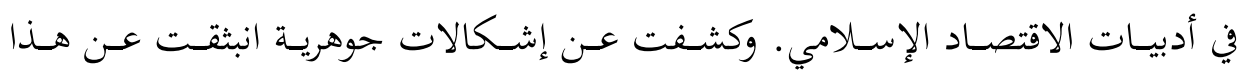
الاستخدام على المستوى المنهجي والنظري والتطبيقي، بـل حتى على مستوى تفسير القرآن الكريم وتأويل آياته.

ويمكن إجمال أهم النتائج التي توصلت إليها الدراسة في فكرة أساسية؛ مؤداهـا أن

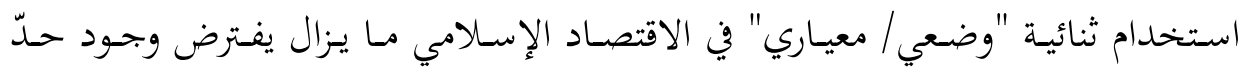
فاصل بين ما يسمى بالوضعي وما يسمى بالمعياري، في حين أوضحت بعض العض الدراسات

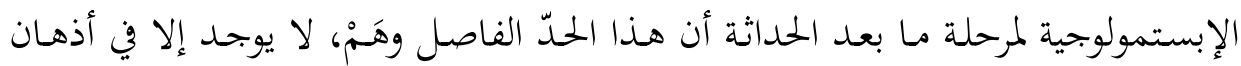
مَن يتحـدثون عنه. ففتحـت هذه الانتقـادات آفاقًا بحثية جديدة لما إيجابياهَا وسلبياها،

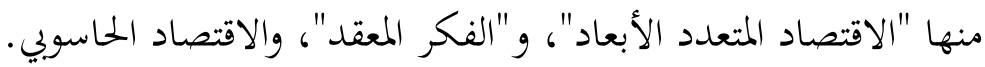

ولبعض البـاحثين في الاقتصـاد الإسـلامي قصـب السبق في الإشـارة إلى عـدم وجـود حدّ فاصل بين ما يوصف بالاقتصاد الوضعي والاقتصاد المعياري، بيد أن انتقادهم لمُ يلقَ تجاوبـاً مـن الزملاء. ويبـدو أن البـاحثين في الاقتصـاد الإسـلامي يميلـون إلى عـدم القـراءة لبعضهم بعضاً، ومواكبة تطورات البحث العلمي في المسائل المنهجية الدقيقة. ونبّه باحثون آخرون على ضرورة التفريق بين ما هو كائن، وما ينبغي أن يكون، وما

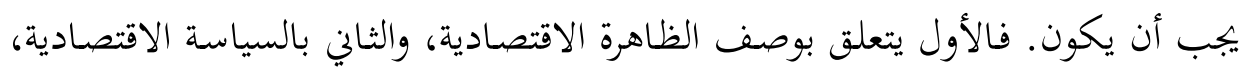

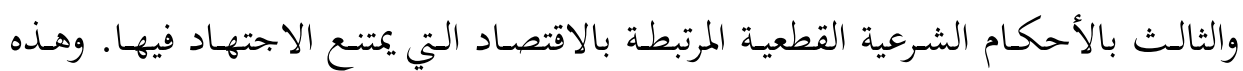

${ }^{68}$ Berthout, Arnaud., Delmas, Bernard et Demals, Thierry (coord.), Ya-til des lois en économie?, Villeneuve-d'Ascq: Presses Universitaires du Septentrion, 2007. 


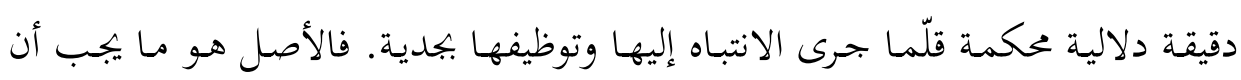

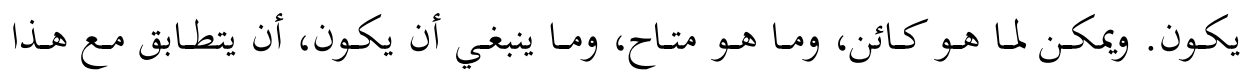

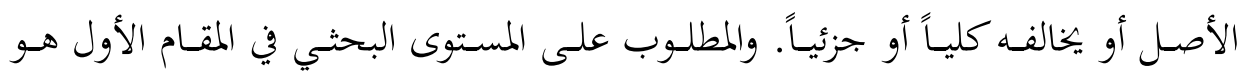

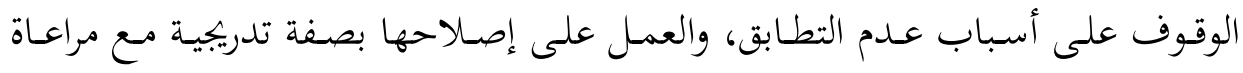
خصائص كل بيئة.

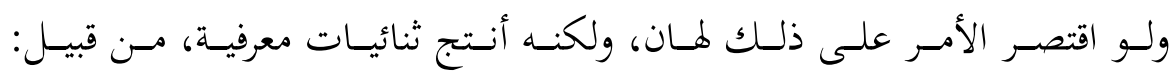

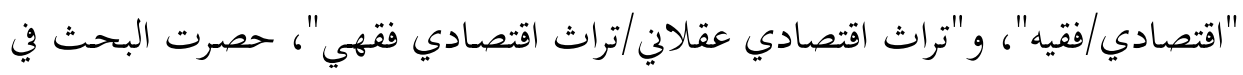

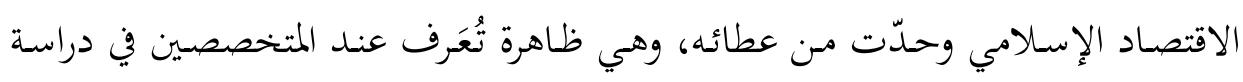

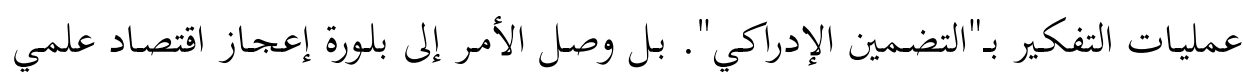

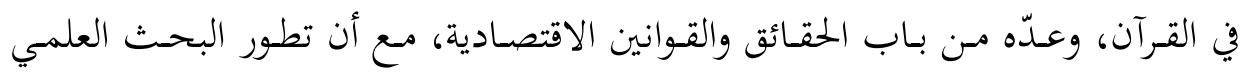

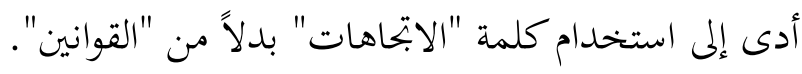

وتخلص الدراسة -على ضوء ما سبق- إلى ضرورة بتحاوز ثنائية "وضعي / معياري"،

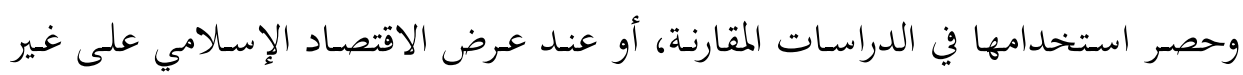

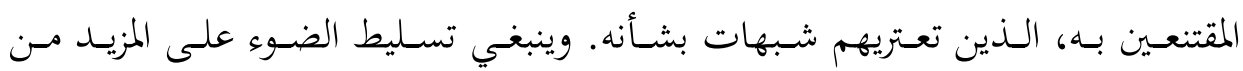

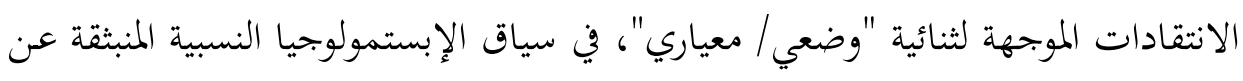

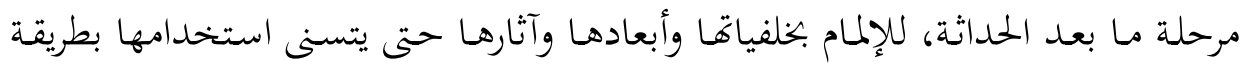

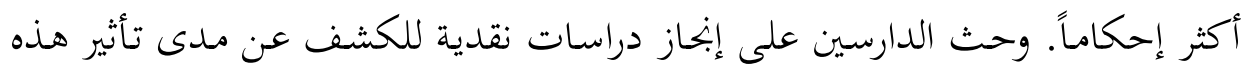
الثنائية في بناء الاقتصاد الإسلامي من الناحية المنهجية والنظرية والتطبيقية. 